\title{
INFLUENCE OF DIETARY FATTY ACIDS ON THE ATHEROGENIC LIPOPROTEIN PHENOTYPE
}

\author{
BRUCE A. GRIFFIN AND ANTONIOS ZAMPELAS
}

Nutrition and Food Safety Research Centre, School of Biological Sciences, University of Surrey, Guildford, Surrey, GU2 5XH

\section{CONTENTS}

INTRODUCTION . . . . . . . . . . . . . . . 2

DEFINITION OF THE ALP AND ITS ASSOCIATED CORONARY

HEART DISEASE RISK . . . . . . . . . . . . . 3

TRIACYLGLYCEROLS AND CORONARY HEART DISEASE RISK . . . . . 3

LOW DENSITY LIPOPROTEIN SUBCLASSES . . . . . . . . . . . . 3

HIGH DENSITY LIPOPROTEIN SUBCLASSES . . . . . . . . . 5

METABOLIC DETERMINANTS OF AN ALP . . . . . . . . . . 5

INSULIN RESISTANCE AND THE ALP . . . . . . . . . . . 5

TRIACYLGLYCEROLS AND VLDL HETEROGENEITY . . . . . . . 6

ROLE OF LIPOPROTEIN LIPASE AND HEPATIC LIPASE, CHOLESTERYL

ESTER TRANSFER PROTEIN AND NEUTRAL LIPID TRANSFERS 7

Cholesteryl ester transfer protein and neutral lipid exchange . . . . . . $\quad 8$

POSTPRANDIAL LIPAEMIA AND THE ALP . . . . . . . . . . 8

THE LDL RECEPTOR PATHWAY . . . . . . . . . . . . . . 9

GENETIC BASIS OF AN ALP . . . . . . . . . . . . . . . . . . 9

INFLUENCE OF DIETARY FATTY ACIDS ON ALP STATUS . . . 10

DIETARY EFFECTS ON PLASMA TRIACYLGLYCEROLS . . . . 10

SATURATED FATTY ACIDS . . . . . . . . . . . . . . . 10

POLYUNSATURATED FATTY ACIDS OF THE N-3 AND N-6 SERIES . . . 11

Effects of PUFA on postprandial lipaemia . . . . . . . . . . . . 11

Effects of dietary n-3 PUFA on gene expression . . . . . . . . . . . . $\quad$. 12

MONOUNSATURATED FATTY ACIDS (MUFA) . . . . . . . . . . 12

Effects of MUFA on postprandial lipaemia . . . . . . . . . . . . . 13

TRANS FATTY ACIDS . . . . . . . . . . . . . . . . . . . 13

DIETARY EFFECTS ON LDL AND LDL SUBCLASSES . . . . . . 14

SATURATED FATTY ACIDS . . . . . . . . . . . . . . . . . 14

Qualitative effects of $S F A$ and the $L D L$ receptor. . . . . . . . . . . $\quad$. 14

Dietary response to fat intake as determined by LDL subclass pattern . . $\quad 14$

PUFA OF THE N-3 AND N-6 SERIES . . . . . . . . . . . 15

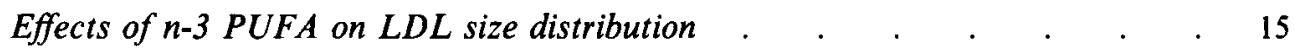

Increases in $L D L$ induced by $n-3$ PUFA . . . . . . . . . . . . 15 
Effects of PUFA on the susceptibility of LDL subclasses to oxidative modification

MONOUNSATURATED FATTY ACIDS OF THE N-9 SERIES . . . . . 16

MUFA and susceptibility of LDL to oxidative modification. . . . . . . 16

DIETARY EFFECTS ON HDL AND HDL SUBCLASSES . . . . 17

SATURATED FATTY ACIDS . . . . . . . . . . . . . . 17

Effects on CETP activity . . . . . . . . . . . . . . . . . . . 17

PUFA OF THE N-3 AND N-6 SERIES . . . . . . . . . . . . . . 17

MONOUNSATURATED FATTY ACIDS OF THE N-9 SERIES . . . . . 18

TRANS FATTY ACIDS

DIET-GENE INTERACTIONS AND INSULIN RESISTANCE . . . 19

DIET-GENE INTERACTIONS . . . . . . . . . . . . . . . . . . . 19

INSULIN RESISTANCE . . . . . . . . . . . . . . . . . . . . 19

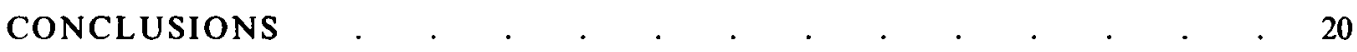

REFERENCES . . . . . . . . . . . . . . . . . . . . 20

\section{INTRODUCTION}

The atherogenic lipoprotein phenotype (ALP) describes a common collection of abnormalities in plasma lipoproteins which confer increased risk of coronary heart disease (CHD) upon normal, healthy individuals. Although its prevalence in Europe is at present unknown, it is predicted that northern Europe will share a similarly high population frequency of the ALP to that seen in north America, where between $30-35 \%$ of middle aged men may be affected (Austin et al. 1990). As defined in the post-absorptive or fasting state, the ALP is characterized by a moderately raised level of serum triacylglycerol (TG), a low level of high density lipoprotein (HDL) and a predominance of abnormally small, dense low density lipoprotein (LDL) and HDL particles. Importantly, levels of total and LDL cholesterol are typically 'normal' or only moderately raised. With the exception of this latter finding, all these features have been associated with an increased atherogenicity of circulating lipoproteins and a predisposition to increased CHD risk. Despite the predicted prevalence of the ALP in European populations, this dyslipidaemia is not currently recognized by routine clinical procedures, largely because of technical difficulties in the measurement of lipoprotein subclasses and the fact that values for serum TG and cholesterol that are characteristic of an ALP usually fall below clinically defined action limits. Heritability studies reveal that up to $50 \%$ of the variability in the expression of an ALP is due to genetic factors, whilst the remaining variability is ascribed to environmental influences, principally diet, smoking and physical inactivity. The relevance of assigning relative contributions to genetic and environmental factors is academic given that in reality the ALP is likely to develop through a complex interaction between dietary factors and specific lipoprotein genes, the expression of which is susceptible to certain dietary stimuli. The atherogenicity of the ALP may well arise from an impaired metabolic capacity to remove TG-rich lipoproteins of dietary origin (chylomicrons (CM) and CM remnants) and very low density lipoprotein (VLDL) of hepatic origin from the circulation, leading to their conversion into small, atherogenic cholesterol-enriched remnants and LDL. An exciting development in this area, that links the metabolism of TG-rich lipoproteins of dietary origin with the ALP, is the recognition of a significant positive relationship between the extent of postprandial lipaemia and fasting TG status. This finding, together with the fact 
that most individuals are in a postprandial state for at least $16 \mathrm{~h}$ a day, may provide a coherent mechanistic basis to explain how diet, especially dietary fatty acids, exert through postprandial events a significant influence on an ALP, and thus on lipoprotein mediated CHD risk.

\section{DEFINITION OF THE ALP AND ITS ASSOCIATED CORONARY HEART DISEASE RISK}

The consistent finding of an inverse association between serum TG and HDL cholesterol in epidemiological studies (Castelli et al. 1977), and the appearance of multiple subpopulations of LDL in hypertriglyceridaemia (Fisher et al. 1980) provided an early indication of the interrelationship between TG-rich lipoproteins and cholesterol. Later studies conducted in individuals with combined hyperlipidaemia led to the identification of a clustering of metabolically related lipoprotein abnormalities in TG-rich lipoproteins, LDL and HDL (Austin \& Krauss, 1986). The same workers extended these observations to a normal, community based population, within which the 'ALP' was first defined and shown to be related to an increase in risk of CHD (Austin $e t$ al. 1990). The original characteristics of an ALP are listed in Table 1. More recently, postprandial studies have linked the expression of this phenotype with an exaggerated postprandial lipaemic response, that is, subjects who express an ALP also show a significant increase in the postprandial level of plasma TG and thus TG-rich lipoproteins in response to the ingestion of a fat-containing meal. For this reason many believe that the definition of an ALP should include indices of enhanced postprandial lipaemia (Table 1).

\section{TRIACYLGLYCEROLS AND CORONARY HEART DISEASE RISK}

The downgrading of TG as a coronary risk factor in multivariate analyses by correction for its covariates such as HDL has received serious criticism, since the abnormalities in TG and HDL may have a common metabolic basis and cannot therefore be treated as covariates. The controversy surrounding TG and CHD risk has largely been resolved by the demonstration of the value of TG as a 'conditional marker' of CHD risk in both primary and secondary trials of CHD prevention (Manninen et al. 1991). Additional support has come from an improved understanding of the pathophysiology of TG. The original hypothesis of Zilversmit (1979) which suggested that atherosclerosis was a postprandial phenomenon has been corroborated by the consistent finding of enhanced postprandial lipaemia in patients with CHD (Patsch et al. 1992; Groot et al. 1991) and in those at increased risk of disease such as non-insulin dependent diabetics (Lewis et al. 1991). Cell culture studies have confirmed that TG-rich lipoproteins and especially CM remnants that are found in abundance in the postprandial phase promote the rapid accumulation of cholesterol within arterial cells (Ellsworth et al. 1986). More important within the context of this review is the capacity of moderate increases in fasting TG to exert an indirect influence on atherogenesis through the promotion of structural changes in LDL and HDL that are typically found in an ALP.

\section{LOW DENSITY LIPOPROTEIN SUBCLASSES}

The predominance of small dense LDL, described by electrophoretic separation as 'LDL subclass pattern B' or as LDL-III on the basis of hydrated density (Fig. 1), has been associated with a three-fold increase in risk of acute myocardial infarction in young men (Austin et al. 1988). More recently, an even greater relative risk of CHD has been 
Table 1. Principal characteristics of the atherogenic lipoprotein phenotype

\begin{tabular}{|c|c|}
\hline Parameter & Fasting Plasma Concentrations \\
\hline $\begin{array}{l}\text { Triglycerides } \\
\text { Small and dense LDL-III (density } 1.044-1.060 \mathrm{~g} / \mathrm{ml} \text { ) } \\
\text { HDL-cholesterol } \\
\mathrm{HDL}_{\mathbf{2}} \text { (large HDL, particle diameter } 9 \cdot 7-12 \cdot 9 \mathrm{~nm} \text { ) } \\
\text { Enhanced postprandial lipaemia } \\
\text { Cholesterol ester enriched VLDL- and CM-remnants } \\
\text { Insulin resistance }\end{array}$ & $\begin{array}{l}1.5-2.3 \mathrm{mmol} / 1 \\
>100 \mathrm{mg} \text { total lipoprotein mass } / 100 \mathrm{ml} \text { plasma } \\
<1 \mathrm{mmol} / 1 \\
<10 \% \text { total } \mathrm{HDL}\end{array}$ \\
\hline
\end{tabular}
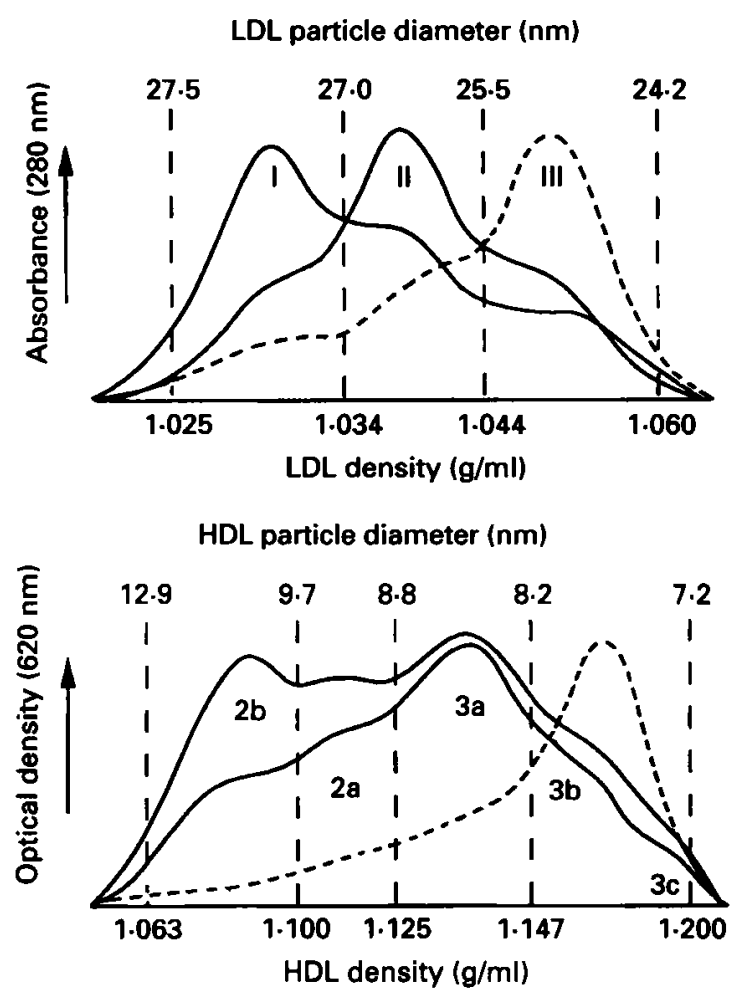

Fig. 1. Plasma LDL and HDL subclasses. Distribution profiles of plasma LDL and HDL subclasses representative of typical normal (non-ALP) — and ALP -_... subjects, as measured by density gradient ultracentrifugation (particle density) and non-denaturing, polyacrylamide, gradient gel electrophoresis (particle size).

associated with a predominance of small dense LDL (Griffin et al. 1994). Several theories have been put forward to explain the increased atherogenicity of small dense LDL. It may be that this LDL subclass has prolonged residence time in the circulation, owing to its slow removal by cellular $L D L$ receptors, thus increasing the time available for its infiltration into the arterial wall. Having crossed into the arterial wall, small dense LDL is believed to be selectively sequestered or 'trapped' in the subendothelial space by components of the extracellular tissue matrix (Camejo et al. 1990). Finally, small dense LDL shows an increased susceptibility to oxidative modification in vitro (de Graaf et al. 1991). If expressed in vivo, this property would promote the internalization of LDL into cells associated with 
the atherosclerotic plaque. A predominance of small dense LDL found in clinically defined hypertriglyceridaemia, as opposed to that found in an ALP, is frequently accompanied by a raised concentration of apoprotein B (Durrington, 1989). As each LDL particle is known to contain a single unit of apo $B$, the concentration of apo $B$ corresponds to the number of LDL particles. A serum level of apo $B>1.3 \mathrm{mg} / \mathrm{ml}$ has been clinically defined as hyperapo- $\beta$-lipoproteinaemia (LDL has ' $\beta$ ' migration on agarose electrophoresis) and is associated with increased CHD risk. However, while this condition is associated with small dense LDL it is not a term that should be used synonymously with the ALP. A predominance of small dense LDL-III is not always associated with raised apo B and the ALP may be expressed at much lower levels of TG than that usually found in patients within hyperapo- $\beta$-lipoproteinaemia.

\section{HIGH DENSITY LIPOPROTEIN SUBCLASSES}

The excretion of cholesterol from the body, whether from peripheral tissues or arterial lesions, can only be achieved by a process of reverse cholesterol transport that is mediated through HDL. This lipoprotein is responsible for the efflux of cholesterol from cells and its transportation back to the liver, either directly or indirectly via its transfer to other lipoproteins. Raised levels of large $\mathrm{HDL}\left(\mathrm{HDL}_{2 \mathrm{~b}+2 \mathrm{a}}\right.$; Fig. 1) have been inversely correlated with CHD risk in a number of case-control studies (Ballantyne et al. 1982; Hamsten et al. 1986). While this is often mistakenly assumed to reflect the protective role of this subfraction, $\mathrm{HDL}_{2}$ is probably not the reverse transport vehicle per se but represents a cholesterol enriched product of an efficient reverse transport system which utilizes very small HDL particles (pre- $\beta$ HDL) or even dissociated HDL protein (apo A-I) for cholesterol efflux from cells (Schmitz \& Lackner, 1993). Whatever the transport vehicle, it is generally assumed that a low level of HDL, such as that found within an ALP (HDL cholesterol $<1 \mathrm{mmol} / 1$ or $380 \mathrm{mg} / \mathrm{l}$ ) is detrimental in terms of CHD risk, as it represents a compromised pathway for the excretion of cholesterol. It is worth noting that there is, as yet, no firm experimental evidence upon which to base this assumption or the commonly held view that raised HDL levels are cardioprotective.

\section{METABOLIC DETERMINANTS OF AN ALP}

\section{INSULIN RESISTANCE AND THE ALP}

Our knowledge of the relationship between insulin resistance, lipoproteins and CHD has evolved to the extent that the ALP is now generally considered to be the dyslipidaemia associated with the insulin resistance syndrome. This is in keeping with the role of TG as the major determinant of the ALP, and the findings of several recent studies that have shown direct linkage between indices of insulin resistance and key features of the ALP such as small dense LDL (Reaven et al. 1993a; Selby et al. 1993). Furthermore, about $25 \%$ of the normal, non-diabetic population are reported to be affected by insulin resistance (Reaven, 1988). This figure is similar to that reported for the ALP and provides further support that the increased risk of CHD in insulin resistance syndrome is mediated through this dyslipidaemia (Despres \& Marette, 1994). A critical review of the effects of insulin on lipid metabolism reveals a major impact of insulin resistance on TG-rich lipoproteins through the failure of this hormone to suppress the activity of hormone sensitive lipase (HSL) and activate lipoprotein lipase (LPL) in adipose tissue (Frayn, 1993). The rate of VLDL production in the liver is partly controlled by the supply of non-esterified fatty acids (NEFA) for TG synthesis. Hence, failure of insulin to perform its normal 


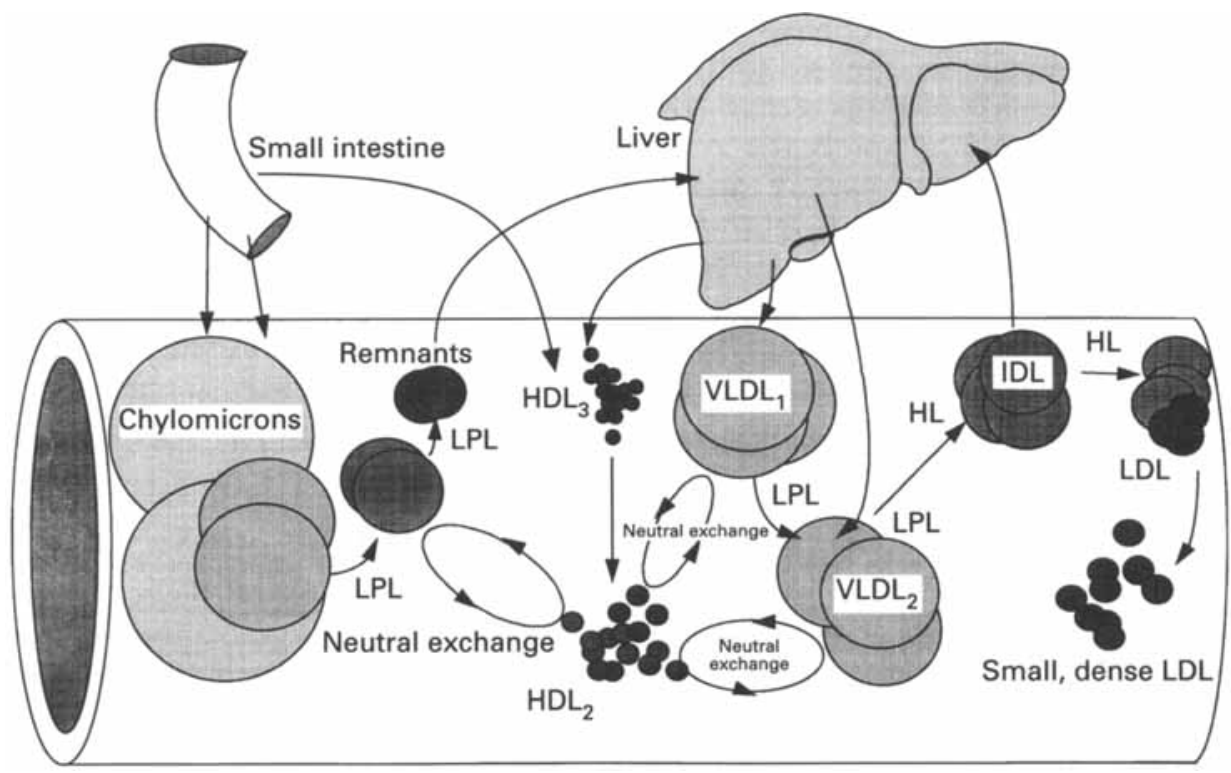

Fig. 2. Lipoprotein transport pathways. Schema showing the inter-relationships between transport pathways of exogenous (dietary), endogenous (hepatic) TG-rich lipoproteins and HDL, and the site of action of lipoprotein lipase (LPL), hepatic lipase (HL) and neutral lipid exchange.

function of suppressing the action of HSL and release of NEFA into the circulation during the postprandial phase will lead to increased synthesis and secretion of VLDL. Insulin also activates LPL during the postprandial phase. As LPL is the rate limiting enzyme for the hydrolysis of TG in CM and VLDL, its impaired activation will result in a reduced capacity to clear TG-rich lipoproteins from the circulation, leading to enhanced postprandial lipaemia and raised fasting TG levels. Within this scenario it is clear that the frequency, rate and extent of entry of exogenous dietary triacylglycerols (as CM) will act as a major perturbation in an already compromised lipid transport system.

\section{TRIACYLGLYCEROLS AND VLDL HETEROGENEITY}

Recent studies indicate that even mild elevations in fasting serum TG such as that found in an ALP (TG 1.5-2.3 mmol/l) are significantly associated with a raised concentration of small dense LDL (Griffin et al. 1994) and reduced levels of HDL (Castelli, 1994). Serum TG levels in the postabsorptive fasting state reflect levels of circulating VLDL which represent the principal transporter of endogenous TG synthesized in the liver (Fig. 2). The liver produces different forms of VLDL that vary in size and density as a result of their varying TG content. Evidence from cell culture studies suggests that the relative distribution of large and small VLDL particles in serum depends upon the supply and nature of lipid substrates (NEFA) that are made available for TG synthesis in the liver (Patsch et al. 1983; Dixon \& Ginsberg, 1993). If this were the case, when large amounts of NEFA became available, either from the diet or lipid storage sites, the production of larger TG-rich VLDL $\left(V_{L D L} S_{t} 60-400\right)$ would be favoured. Conversely, lower NEFA levels would tend to favour the production and secretion of smaller VLDL particles (VLDL,$\left.S_{7} 20-60\right)$. The majority of LDL in the circulation is derived from VLDL via a delipidation cascade produced by the action of endothelial lipases in the lining of blood vessel walls of the peripheral (LPL) and hepatic circulations (hepatic lipase; HL). Kinetic experiments with 


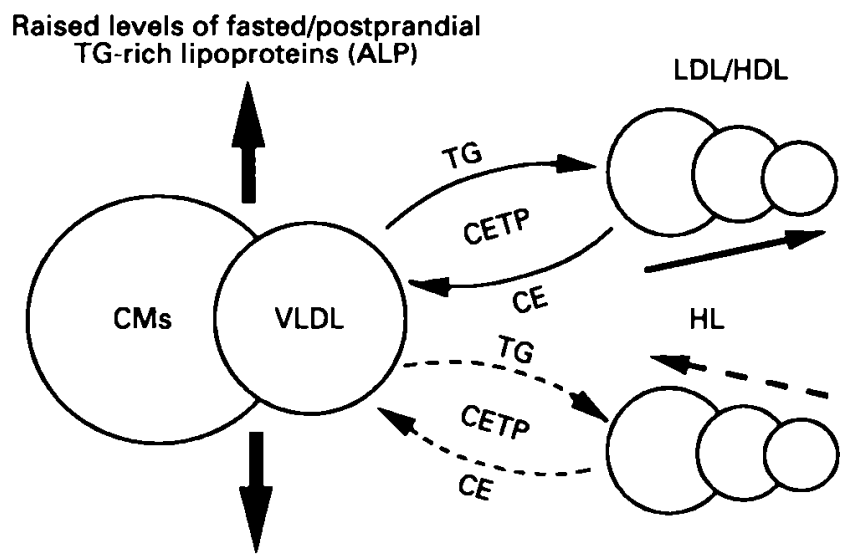

Low levels of fasted/postprandial

TG-rich lipoproteins

Fig. 3. Neutral lipid exchange as a mechanism for the reduction in the particle size of LDL and HDL. Under normal circumstances when fasting TG levels are low the rate of transfer of TG from TG-rich lipoproteins to LDL and HDL in exchange for cholesteryl esters (CE) is low. An increase in the concentration of TG-rich lipoproteins, either in the form of chylomicrons and their remnants or large VLDL, accelerates this process leading to transient enrichment of LDL and HDL with TG. This additional TG is then hydrolysed by hepatic lipase (HL) which generates small and dense particles.

tracers have shown that the precursor-product relationship between VLDL and LDL is affected not only by the amount of VLDL but also by the type of VLDL (Shepherd \& Packard, 1987), the latter determining the quantity and quality of LDL. Under normal circumstances when fasting TG levels are low, large VLDL, after rapid delipidation, become VLDL remnants that are removed directly from the circulation without being converted into IDL and then LDL (Fig. 2). As VLDL remnants are removed by membrane receptors in a manner similar to that described for CM remnants, large VLDL are often referred to as the 'liver's chylomicrons'. On the other hand, the smaller $\mathrm{VLDL}_{2}$ are progressively delipidated into IDL and then LDL and are often referred to as 'pre-LDL'. Although a relationship between VLDL heterogeneity and the ALP is not yet established, the consistent finding of small dense LDL and HDL in conditions characterized by the presence of large TG-rich VLDL 1 such as diabetes and obesity (James \& Pometta, 1991; Fisher et al. 1993), suggests that $\mathrm{VLDL}_{1}$ is a major determinant of the remodelling of $\mathrm{LDL}$ and $\mathrm{HDL}$ into smaller and denser particles by mechanisms that involve the donation of TG in exchange for cholesterol esters (see neutral lipid exchange and Fig. 3). In contrast, the overproduction of $\mathrm{VLDL}_{2}$ is associated with increases in LDL mass as found in common hypercholesterolaemia (Gaw et al. 1995). It is important to appreciate that levels and subclass distribution of HDL are also affected by serum TG levels and VLDL heterogeneity.

\section{ROLE OF LPL AND HL, CHOLESTERYL ESTER TRANSFER PROTEIN AND NEUTRAL LIPID TRANSFERS}

As the rate limiting enzyme for the hydrolysis of TG carried in CM and VLDL, LPL is regarded as one of the major determinants of postprandial and fasting TG levels. Its activity is regulated by apoproteins associated with TG-rich particles and HDL, such as apo C-II which activates LPL or apo C-III which inhibits its action. Endothelial lipases show a preference for lipoproteins of different sizes (Nicoll \& Lewis, 1980; Jackson et al. 1987). LPL hydrolyses the TG within larger lipoproteins such as CM and VLDL in vitro 
and is even reported to express a preference for TG contained in CM rather than in VLDL through mechanisms that are incompletely understood. In contrast, HL acts primarily on smaller lipoproteins in the range of IDL, LDL and HDL and small CM remnants. The reason why these enzymes show a preference for lipoproteins of different sizes is not clear but may relate to the exposed surface area of the particle, the packing pressure of its lipid bilayer or relative exposure of lipid substrate. As an enzyme that is activated by insulin, adipose tissue LPL may be a key determinant of the ALP, through its role in the regulation of TG levels, particularly during the postprandial phase. Physical exercise stimulates the activity of LPL in skeletal muscle. The resulting lower fasting TG levels may explain changes in lipoproteins that follow acute bouts of exercise and differences in lipoprotein profile between athletes and non-athletes (Dufaux et al. 1982). The activity of HL has been implicated in the generation of small dense LDL and HDL (Zambon et al. 1993; Watson et al. 1994), though evidence for regulation of this enzyme by dietary or hormonal factors is lacking.

\section{Cholesteryl ester transfer protein and neutral lipid exchange}

The transfer of TG from TG-rich lipoproteins to smaller lipoproteins in exchange for cholesteryl esters has been known for some time to occur by a mechanism of neutral lipid exchange (Nichols \& Smith, 1965). This process occurs under the influence of lipid transfer proteins the best characterized of which is cholesteryl ester transfer protein (CETP). The net mass transfer of TG from large TG-rich lipoproteins to smaller lipoproteins in exchange for cholesterol results in the transient enlargement of the smaller lipoproteins which are then reduced in size by the action of lipases such as HL (Fig. 3). The extent to which this reaction occurs is a direct function of the concentration of donor TG-rich lipoproteins (large $\mathrm{VLDL}_{1}, \mathrm{CM}$ and CM remnants) and thus serum TG levels. Raised TG levels can therefore promote shifts in the size and density distribution of both LDL and HDL towards small dense particles via excessive neutral lipid exchange as illustrated in Fig. 3. In addition, turnover studies have shown that small, dense HDL are removed more rapidly from the circulation and thus are unavailable for reverse cholesterol transport. In this way, neutral lipid exchange may promote low levels of $\mathrm{HDL}_{2}$ that characterize an ALP. The work of Lagrost et al. $(1990,1993)$ and many others would suggest that the transfer capacity of CETP may be rate limiting in this reaction, though this theory is controversial as the kinetics of the CETP reaction have been defined in vitro. With the possible exception of the rate condition of inherited CETP deficiency, there is usually little correspondence between the activity or mass of plasma CETP and lipoprotein subclasses and these in vitro findings. This would imply that whilst the activity of CETP is required for the exchange of neutral lipids in vivo, it is not necessarily rate limiting. Whatever the impact of CETP on lipoprotein subclasses, a number of reports have claimed that its activity can be modified by dietary fatty acids, and these will be reviewed.

\section{POSTPRANDIAL LIPAEMIA AND THE ALP}

The impaired removal of dietary TG in the form of $\mathrm{CM}$ and partly hydrolysed CM remnants following the ingestion of a fat-containing meal is likely to enhance neutral lipid exchange through the persistence in the circulation of TG-rich donor lipoproteins and thus increased substrate availability (Figs 2,3 ). There is also the possibility of competition between large $\mathrm{VLDL}_{1}$ and $\mathrm{CM}$ and large $\mathrm{CM}$ remnants for a common saturable lipolytic pathway during the postprandial phase (Brunzell et al. 1973) when TG levels can be increased as much as three-fold over baseline values for a period of several hours. The idea that the degree of postprandial lipaemia could be determined by fasting TG level, that is 
by levels of large TG-rich VLDL, has been suggested by Weintraub et al. (1988) and more recently by others (O'Meara et al. 1992; Chen et al. 1993). The postprandial shift in HDL subclass distribution away from the cholesterol-enriched $\mathrm{HDL}_{2}$ towards the smaller $\mathrm{HDL}_{3}$ and the significant inverse relationship between the extent of postprandial lipaemia and HDL cholesterol provide convincing evidence for the impact of postprandial events on neutral lipid exchange (Patsch et al. 1987). The relationship between postprandial lipaemia and LDL subclasses is less well established, probably because the remodelling of LDL subclasses is mediated through longer term, indirect influences of postprandial events on fasting VLDL levels. There is, however, recent evidence for a significant inverse relationship between LDL size and the magnitude of postprandial lipaemia (Nikkila et al. 1994).

\section{THE LDL RECEPTOR PATHWAY}

Although the role of the $\mathrm{LDL}$ receptor pathway in the regulation of total and $\mathrm{LDL}$ cholesterol levels is well established, it is not central to the understanding or development of the ALP, as this dyslipidaemia is not usually associated with raised levels of LDL. Nevertheless, the existence of structural heterogeneity in LDL raises the possibility that different LDL subclasses will be metabolically distinct with respect to their interaction with the LDL receptor and thus express differences in binding affinity. In this way, diet-induced changes in the activity of the LDL receptors could influence the distribution of LDL subclasses. Cell culture studies indicate that large and small LDL species (LDL-I, III) bind with lower affinity to the receptor compared to the LDL of intermediate size and density (LDL-II) (Nigon et al. 1991). Human and animal studies show that LDL of large and intermediate size are preferentially removed in response to drug induced stimulation of LDL receptors, leaving plasma relatively enriched in small dense LDL (Beltz et al. 1987; Franceschini et al. 1990). The discrepancy in the uptake of large LDL-I between these different studies may be explained by the recent finding that this LDL subclass is rapidly converted in vivo (Caslake et al. 1994) into what has been shown to be 'receptor active' LDL-II in cell culture.

\section{GENETIC BASIS OF AN ALP}

The ALP is believed to develop through genetic-environmental interactions (Austin, 1991). A number of common mutations in the LPL and functionally related apoprotein genetic loci have been identified as possible susceptibility genes that interact with diet to produce changes in postprandial and fasting TG levels. In addition to the control of peripheral lipolysis, the genetic regulation of the enzymes of intracellular lipolysis in adipose tissue (hormone sensitive lipase, HSL) and hepatic lipogenesis may be equally important as mechanisms that are genetically susceptible to diet. The role of diet inducible gene transcription factors in the liver may be particularly important in this context as potential determinants of the regulatory influence of specific fatty acids on energy metabolism.

The apo E polymorphism (apo $\epsilon 2$ allele) has also been implicated in the impaired removal of dietary CM and CM remnants via its influence as a ligand for the CM remnant receptor and may contribute to variation in the postprandial response. However, despite the well known relationship between the $\mathrm{E} 2$ polymorphism and low LDL levels that results from an upregulation of LDL receptors (Uterman, 1987), no relationship could be found between E phenotype and the distribution of LDL particle size in a postprandial study by Nikkila et al. (1994). More recently, apo E phenotype has been related to the magnitude of response of LDL subclasses to a reduced fat diet, with the greatest reduction in large LDL occurring in E4/E4 subjects (Dreon et al. 1995). Interestingly, the apo $\epsilon 4$ allele has also been 
associated with increased CHD risk in non-insulin dependent diabetics and seems to disturb the normal relationship between insulin and TG (Despres \& Marette, 1994).

The predominance of small dense LDL in an ALP in various population groups has been ascribed in complex segregation analysis to the effects of a single major gene with a polygenic mode of inheritance (Austin, 1993). The nature of this single gene has yet to be elucidated, though the LDL receptor gene on the short arm of chromosome 19, also the site of the insulin receptor gene, is a favoured candidate (Nishina et al. 1992).

\section{INFLUENCE OF DIETARY FATTY ACIDS ON ALP STATUS}

A recent government report from the Committee on Medical Aspects of Food Policy (Department of Health, 1994) recognized that "the quality and quantity of fat are fundamental and modifiable determinants of plasma lipid levels". 'Plasma lipids' in this context refers to traditional, cholesterol based CHD risk factors. The report continues to promote the inflated perception of the efficacy of cholesterol lowering diets in a free living population as reviewed by Ramsay et al. (1991). It also gives little consideration to TG and dismisses the impact of n-3 polyunsaturated fatty acids (PUFA) on TG because of their 'minimal' effects on HDL and LDL cholesterol levels and their potentially adverse effects in raising $\mathrm{LDL}$ cholesterol in hypertriglyceridaemic patients. The ALP is a common, high risk phenomenon associated with an intolerance to dietary fat with a resultant proliferation of remnant lipoproteins of postprandial origin and modifications in LDL structure, neither of which is reflected in the cholesterol content of lipoproteins. As such, there is a clear need for a shift in emphasis away from cholesterol so that, in future, dietary studies can take full advantage of the most recent developments in our understanding of TG metabolism in relation to $\mathrm{CHD}$.

The identification of TG as the major determinant of the ALP establishes this lipid as the primary target for dietary fatty acid modifications as a means of correcting the lipoprotein abnormalities of an ALP, with emphasis on the attenuation of enhanced postprandial lipaemia. The effects of TG on LDL and HDL subclasses are modulated through the combined actions of endothelial lipases (LPL, HL), lipid transfer proteins (CETP) and lipoprotein receptors, all of which may be subject to dietary influence. Finally, weakness in the inter-relationships between insulin resistance, serum lipids and lipoproteins and diet has been ascribed to underlying genetic variation. The ALP with its strong genetic basis and metabolic links with insulin resistance offers the most relevant phenotypic classification with which to address the influence of genetic susceptibility to diet in normal, free-living populations.

\section{DIETARY EFFECTS ON PLASMA TRIACYLGLYCEROLS}

\section{SATURATED FATTY ACIDS}

The replacement of dietary saturated fatty acids (SFA) with unsaturated fatty acids is frequently accompanied by a lowering of fasting serum TG (Durrington, 1989). The question arises, can these effects be attributed to the various properties of the unsaturated fatty acids themselves or are they simply permissive effects produced by the removal of the SFA. The established cholesterol raising properties of dietary SFA have overshadowed their effects on TG, with the result that greater importance has been attached to the nature of the substitute, unsaturated fatty acids.

The chronic and acute ingestion of foods enriched in saturated fats produces enhanced postprandial lipaemia (Demacker et al. 1991; Zampelas et al. 1994). The reason for this effect is not clear but may relate to saturated TG producing smaller CM which show a 
delayed clearance from the circulation via LPL (Levy, 1991; Murphy et al. 1993). In contrast to the potentially beneficial impact of these postprandial effects on the ALP, a recent cross-sectional study which compared rural and urban populations found that a lower intake of dietary SFA, but not total fat, in the rural population was associated with raised triacylglycerols, small LDL size and low HDL levels (Campos et al. 1991). The findings of this particular study were, however, confounded by high intakes of simple carbohydrates in the rural population that led to the phenomenon of carbohydrate-induced hypertriglyceridaemia.

\section{POLYUNSATURATED FATTY ACIDS OF THE N-3 AND N-6 SERIES}

Linoleic acid (C18:2, $n-6$, found in many vegetable oils) is normally the principal dietary PUFA contributing to the commonly used polyunsaturated: saturated fatty acid ratio. In most studies, the replacement of saturates with linoleic acid reverses nearly all the effects on lipids and lipoproteins produced by long chain SFA.

The TG lowering action of linoleate-rich diets has been described as an inconsistent phenomenon (Grundy \& Denke, 1990). The TG lowering effects of n-6 PUFA in particular may be restricted to individuals with an overproduction of VLDL. These effects could result from the inhibitory effects of linoleic acid on lipogenic enzymes involved in the synthesis of hepatic fatty acids (fatty acid synthetase) and TG (phosphatidate phosphohydrolase and diacylglycerol acyl transferase (Herzberg, 1991; Schmidt et al. 1993). Although an inhibition of fatty acid synthesis has been shown to limit the production of VLDL in rats, the quantitative significance of this mechanism in western man is negligible, given that fatty acid requirements are satisfied from dietary intake. Dietary long chain n-3 PUFA from fish oils, which includes as the biologically active species eicosapentaenoic acid $(20: 5, n-3)$ and docosahexaenoic acid $(22: 6, n-3)$, have similar inhibitory effects on these enzymes and VLDL production, but in contrast to $n-6$ PUFA they markedly reduce postprandial and fasting TG. The incorporation of PUFA into VLDL should, through their relatively greater molecular volume, lead to the production of larger VLDL particles $\left(\mathrm{VLDL}_{1}\right)$ which, according to kinetic turnover studies, are cleared rapidly from the circulation without being converted into LDL (Shepherd \& Packard, 1987). This is supported by the findings of several groups who have shown that $n-6$ enriched diets are followed by a decrease in the rate of synthesis of VLDL and a fall in LDL, that is presumably derived from smaller $\mathrm{VLDL}_{2}$ (Illingworth et al. 1981; Turner et al. 1981; Cortese et al. 1983). Although this qualitative theory is attractive, a decrease in the absolute number of VLDL particles that are synthesized is likely to make a greater contribution to the decrease in LDL.

In common with $n-6$ series, dietary $n-3$ PUFA also suppress the production of VLDL in man (Nestel et al. 1984) but may produce different qualitative effects upon VLDL from those produced by n-6 PUFA by inducing a shift in the distribution of VLDL subclasses towards predominantly small VLDL (VLDL $\mathrm{S}_{2} 20-60$ ) (Harris, 1989). While this could be viewed as a secondary effect resulting from the efficient removal of larger $V L D L$ particles, the precursor-product relationship between $\mathrm{VLDL}_{2}$ and LDL would suggest that it contributes to the increases in LDL that can occur following n-3 PUFA supplementation in normal and hypertriglyceridaemic groups (see LDL subclasses).

\section{Effects of PUFA on postprandial lipaemia}

In addition to their effects on VLDL metabolism, dietary PUFA may exert a significant effect on the ALP by attenuating both the duration and magnitude of postprandial lipaemia compared with highly saturated diets (Harris et al. 1988a; Weintraub et al. 1988; 
Demacker et al. 1991). This effect is markedly greater for the n-3 PUFA which can reduce postprandial TG levels by up to $60 \%$.

Both acute and chronic consumption of n-3 PUFA have been associated with reductions in postprandial response, characterized by reductions in CM and CM remnants. There are a number of explanations for these effects. First, the size and fatty acid composition of CM may increase their ability to compete with large VLDL as substrates for LPL (Levy et al. 1991). Secondly, an increase in post-heparin LPL activity has been observed following a fish oil acute test meal, compared with a SFA-rich meal (Zampelas et al. 1994), though several other studies which examined long term intervention with fish oils refute these findings (Weintraub et al. 1988; Nozaki et al. 1991). While these mechanisms may all be operative in the short term, the greater impact of a habitual intake of n-3 PUFA on the attenuation of postprandial lipaemia would favour longer term effects, possibly mediated through the upregulation of LPL gene expression in adipose tissue as demonstrated in the rat (Murphy et al. 1993). This theory of increased catabolism via LPL is somewhat controversial, not only because of evidence to suggest that n-3 PUFA decrease the rate at which $\mathrm{CM}$ are produced and secreted rather than increasing their catabolism (Harris \& Muzio, 1993), but also because n-3 PUFA are not usually associated with changes in the activities of LPL and HL in post-heparin plasma, despite significant decreases in TG (Nozaki et al. 1991). This finding highlights other possible explanations for the TG lowering property of n-3 PUFA, which is to inhibit lipogenic enzymes responsible for TG synthesis in the liver and enterocyte (Marsh et al. 1987; Rustan et al. 1988) and decrease the synthesis and secretion of newly synthesized TG in cells of the human intestine (Murthy et al. 1990).

\section{Effects of dietary $n-3$ PUFA on gene expression}

Dietary n-3 PUFA are among a number of substances, such as the fibric acid derivatives, that may activate nuclear receptors in the liver that function as gene transcription factors. These receptors are part of the steroid hormone receptor superfamily, two of which include the peroxisome proliferator-activated receptor and the apo A-I regulatory protein. The induction of the former by dietary n-3 PUFA in rats promotes the $\beta$-oxidation of fatty acids in peroxisomes, whereas activation of the latter may repress transcription of the apo C-III gene, removing the inhibitory effects of this peptide on the activity of LPL. The recent detection of peroxisome proliferator-activated receptor in adipose tissue (Tontonoz et al. 1994) has major implications for the impact of dietary n-3 PUFA on gene expression in the postprandial phase.

\section{MONOUNSATURATED FATTY ACIDS (MUFA)}

Compared to a typical American diet (10\% total calories MUFA), a modified 'Step I' diet of the American Heart Association enriched with olive oil (18\% total calories MUFA) produced no significant effects on fasting TG levels in healthy, normolipaemic young men (Ginsberg et al. 1990). MUFA-rich diets were also shown to have no significant effects on TG levels when compared with PUFA-rich diets (Berry et al. 1991; Wardlaw et al. 1991; Nydahl et al. 1994a). A significant decrease in TG has been reported in similar subjects given diets rich in oleic acid ( $54 \%$ total calories MUFA) compared with a high SFA diet, but in the same study, the oleic acid-rich diet was not as effective in lowering TG as diets enriched with mixtures of high PUFA and MUFA (Chan et al. 1991). In contrast, Wardlaw \& Snook (1990) compared SFA, n-6 PUFA and MUFA-rich diets and found that the PUFA and MUFA diets significantly reduced TG levels relative to the SFA diet. Thus, current evidence would indicate that MUFA enriched diets may have some effects on TG 
levels in normolipaemic men when compared with experimental diets enriched with SFA. Interestingly, MUFA enriched diets have also been associated with either no change or increases in TG levels when compared with a high PUFA diet (Mata et al. 1992a,b respectively), or a high SFA diet (Mata et al. 1992b), though these latter changes were confined to subjects with the highest body weight.

\section{Effects of MUFA on postprandial lipaemia}

Literature on the postprandial effects of MUFA on the ALP and on lipoprotein metabolism in general is limited. It is difficult to reach definite conclusions from the information that is available on postprandial changes in plasma TG, following either acute test meals or a standard test meal after a dietary intervention period. Studies which compared various acute test meals enriched with either MUFA or PUFA showed no significant effects on postprandial triglyceride levels (de Bruin et al. 1993). Lichtenstein et al. (1993) showed a similar lack of response to acute test meals following intervention periods with n-6 PUFA and MUFA enriched diets. In contrast, when periods of olive oil and fish oil supplementation were compared, the former increased postprandial TG levels in the CM fraction following a standard test meal (Brown \& Roberts 1991).

It has become apparent that metabolic events in the postprandial phase cannot be adequately described by following changes in TG levels or even lipid markers of CM metabolism such as retinyl palmitate. A recent advance in this area has been the measurement of apoprotein B-48, the only form of apo B found in human CM that can be used as a specific marker of $\mathrm{CM}$ and $\mathrm{CM}$ remnant metabolism. This assay, when used in conjunction with the retinyl palmitate loading technique, has provided new insight into the effects of different dietary fatty acids on the magnitude and the extent of postprandial lipaemia. In the study of de Bruin and co-workers, even though postprandial TG levels were not different following soybean (n-6 PUFA) or the olive oil test meal, the postprandial decrease in HDL was less with the olive oil test meal, whilst both retinyl palmitate concentration (area under the curve) in the CM and apo B-48 in the CM remnant fractions were higher following the olive oil $v$. the soybean oil meal. In addition, a correlation between the slow removal of CM remnant on the olive oil diet with $\mathrm{HL}$ activity led the authors to postulate that the CM remnants produced by the acute ingestion of olive oil were smaller and compete with HDL for a receptor pathway that is dependent on HL, whereas the n-6 PUFA-rich CM and CM remnants were possibly removed by an additional nonenzymic pathway (Brouwer et al. 1993). The 'HL hypothesis' was suggested by these authors to explain the HDL 'sparing effect' associated with MUFA, though an alternative hypothesis could be that olive oil CM-TG are not hydrolysed as efficiently as those produced by $\mathrm{n}-6$ PUFA so that HL has to act on these particles for longer in order to make them recognizable by hepatic receptors. Although these studies are inconclusive with respect to the effects of MUFA meals or diets on postprandial lipaemic responses, they highlight the metabolic importance of small CM remnants that have been recently detected by the analysis of apo B-48 within IDL and LDL density intervals (Isherwood et al. 1995).

\section{TRANS FATTY ACIDS}

Recent interest in dietary trans fatty acids has grown from their similarity to SFA and potentially adverse effects on plasma lipoproteins. While more than half the trans fatty acids in the diet originate from vegetable or fish oils rich in $n-6$ or $n-3$ PUFA respectively that have undergone partial hydrogenation during food manufacturing processes, they also occur naturally in dairy products. Although consumption of trans fatty acids, is still relatively low in westernized countries, it has increased from $3-4 \%$ of the daily energy 
intake in the USA (Senti, 1985) to 5-7\% (Mensink \& Katan, 1993), and speculations are that the figure may be even higher. While trans fatty acids are reported to increase the concentration of LDL and decrease HDL relative to their cis isomers (Mensink \& Katan, 1993; Judd et al. 1994), some studies have shown TG levels to be unaffected (Abbey \& Nestel, 1994).

\section{DIETARY EFFECTS ON LDL AND LDL SUBCLASSES}

\section{SATURATED FATTY ACIDS}

In common with dietary cholesterol, the capacity of the long chain SFA C:12, C:14 and $C: 16$ to raise $\mathrm{LDL}$ cholesterol are well founded and thought to arise through the suppression of LDL receptor synthesis in the liver (Grundy \& Denke, 1990). Hence, the replacement of dietary saturates with unsaturates is accompanied by predictable quantitative effects resulting from the enhanced clearance of LDL from the circulation. These include a fall in the number of circulating LDL particles, apoprotein B and serum cholesterol. The effects of saturated 'atherogenic' diets on LDL structure of non-human primates is well documented but will not be considered within the context of the ALP because of significant phylogenetic differences in lipoprotein heterogeneity between species.

\section{Qualitative effects of SFA and the LDL receptor}

Theoretically, a stimulation of LDL receptors in response to the removal of dietary SFA in humans can induce a preferential clearance of larger, relatively cholesterol-rich LDL species, leaving the plasma relatively enriched in small dense LDL. This effect has been demonstrated in guineapigs (Witztum et al. 1985) and is a common finding in humans on cholesterol lowering drugs that stimulate this receptor pathway (Young et al. 1989; Franceschini et al. 1990; Griffin et al. 1992). While the short term outcome of this effect on the distribution of LDL subclasses appears to be unfavourable in terms of CHD risk, this is probably outweighed by the reduction in total circulating LDL mass that is likely to accompany a reduction in SFA. The effect of dietary lipid saturation on the metabolism of two LDL subfractions of the guineapig has been recently examined by Fernandez et al. (1993). In this study, animals fed a diet enriched in SFA showed a slower clearance of LDL and a predominance of larger LDL as compared to animals fed a PUFA enriched diet. The latter animals also showed a shift in LDL towards smaller and dense LDL. Although these observations would be in accord with potentiation of receptor activity on the PUFA diet leading to the uptake of large 'receptor active' LDL, with the opposite finding on the SFA diet, the study showed that, in the guineapig, small dense LDL was catabolized more rapidly than its larger and lighter counterparts, a finding confirmed for the catabolism of human LDL in the same animal by Swinkels et al. (1990), but not by Witztum et al. (1985). These inconsistencies are difficult to resolve and their relevance to humans questionable in view of the limited amount of data available on the effects of SFA on LDL subclasses and the inevitable differences between human and animal models. For example, serum TG levels in the guineapig are low compared to humans and as such are not a major determinant of LDL subclass distribution.

\section{Dietary response to fat intake as determined by $L D L$ subclass pattern}

A recent dietary intervention trial examined the response of men subdivided on the basis of their LDL subclass pattern (pattern A (normal) or pattern B (small dense)) to a high fat ( $46 \%$ total calories) followed by a low fat ( $24 \%$ total calories) diet (Dreon et al. 1994). LDL cholesterol was shown to fall in both groups on moving from the high to low fat diet. 
However, pattern B subjects showed greater decreases in apo B and LDL cholesterol than pattern A subjects. Furthermore, over $40 \%$ of the pattern A subjects converted to pattern $B$ on the low fat diet. These findings indicate that individuals with the abnormal, $L D L$ pattern B may achieve greater benefits from dietary modification through reductions in the number of LDL particles as compared with individuals with normal, LDL pattern A, within whom the cholesterol lowering arises from a shift from a predominantly cholesterolrich LDL to a relatively cholesterol-poor, small dense LDL subclass. This latter finding has been recently confirmed by the same workers who showed that the magnitude of the apparent shift in LDL subclasses in response to a reduced fat diet (SFA replaced by carbohydrate representing $60 \%$ total energy content) was related to $E$ phenotype in the increasing order of E3/2 to E3/3 to E4/3, E4/4 (Dreon et al. 1995). As already mentioned, the impact of this change in LDL subclasses in terms of increased CHD risk is likely to be offset by a fall in total LDL mass.

\section{PUFA OF THE N-3 AND N-6 SERIES}

It can be speculated that the influence of dietary n-6 and n-3 PUFA on the distribution of LDL subclasses will reflect their capacity to reduce the concentration of TG-rich lipoproteins (Fig. 3). This includes VLDL in the fasted state and CM and large CM remnants in postprandial plasma. However, while the direct influence of dietary n-6 PUFA on discrete LDL subclasses has yet to be elucidated, data relating to the lipid and protein composition of total LDL suggest that n-6 PUFA have minimal effects on LDL heterogeneity.

\section{Effects of n-3 PUFA on LDL size distribution}

In contrast to the expected effects of dietary n-6 PUFA, failure to demonstrate qualitative effects of n-3 PUFA on LDL particle size in normal and hypertriglyceridaemic groups is surprising given their potent TG-lowering action (Sullivan et al. 1986; Homma et al. 1991; Nenseter et al. 1992). A significant redistribution of LDL particle size can be inferred from alterations in LDL composition, such as a change in the cholesterol or lipid to protein ratio. However, data from Harris (1989) and others (Nestel, 1986; Sullivan et al. 1986) indicate that n-3 PUFA have no significant effects on LDL composition. In this respect, there are two points worth noting. First, the effects of dietary n-3 PUFA on the quantitative distribution of visually discrete LDL subclasses, as resolved by density gradient centrifugation procedures, has not been reported. Secondly, it is quite possible that quantitative changes could occur in LDL subclasses without significantly altering the lipid or protein composition of total plasma LDL. A recent study reported significant increases in LDL particle diameter accompanied by a $30 \%$ fall in TG in response to $\mathrm{n}-3$ PUFA supplementation in patients with combined hyperlipidaemia (Contacos et al. 1993). The finding of an increase in LDL particle size in response to n-3 PUFA was corroborated by Suzukawa et al. (1994) but not by Homma et al. (1991) who actually found decreases in LDL particle size.

\section{Increases in $L D L$ induced by $n-3$ PUFA}

The most consistent finding in n-3 PUFA studies regarding lipoprotein heterogeneity is an increase in small VLDL ( $\left.\mathrm{S}_{\mathrm{f}} 20-60\right)$ (Sullivan et al. 1986; Harris, 1989). As the main progenitor of LDL this is believed to account for the n-3 PUFA induced increases in LDL mass that occur in normolipidaemic and hypertriglyceridaemic subjects (Sullivan et al. 1986; Harris et al. 1988 b; Levine et al. 1989; Deck \& Radack, 1989). This LDL raising property, which occurs either through increased conversion of VLDL (Huff \& Telford, 1989) or competition between VLDL and LDL for the LDL receptor (Gianturco \& 
Bradley, 1991), may be more frequently associated with the use of n-3 PUFA capsule supplements. The substitution of SFA for n-3 PUFA derived from dietary fish oils is reported to produce either varying effects, no effects or even significant decreases in LDLcholesterol and apo B (Nestel et al. 1984; Hänninen et al. 1989; Childs et al. 1990; Friday et al. 1991 ; Connor et al. 1993; Illingworth \& Schmidt, 1993; Jiang \& Sim, 1993). Different species of fish have also been shown to produce variable effects on LDL levels (Gerhard et al. 1991). These findings might suggest that it is the increase in total fat intake associated with capsule supplements and not the n-3 PUFA per se which causes the increase in LDL cholesterol levels. However, differences in energy intake over a short period of oil supplementation are usually negligible and subjects taking capsule supplements have also been shown to compensate and thus maintain an energy balance.

\section{Effects of PUFA on the susceptibility of LDL subclasses to oxidative modification}

The oxidative modification of $\mathrm{LDL}$ is thought to be a prerequisite for the deposition of LDL cholesterol in the artery wall. A recent examination of the effects of linoleate and oleate enriched diets on the susceptibility of LDL subfractions to oxidative modification suggested that the increased susceptibility of small dense LDL (LDL-III) to oxidation was linked to the preferential enrichment of this subfraction with linoleic acid (Reaven $e t$ al. 1994). This finding was consistent with earlier work that ascribed at least part of the increase in oxidative susceptibility of small dense LDL to its higher ratios of 18:2 and 20:4 (arachidonic acid) to vitamin E levels (de Graaf et al. 1991). The reason why small dense LDL should contain higher levels of PUFA is not clear. The increased oxidative susceptibility of PUFA enriched LDL and its rapid removal by scavenger receptors has been offered as another possible but unlikely explanation for the LDL lowering effects of dietary PUFA (Norum, 1992). Far from being a favourable effect, this could be regarded as a potentially pro-atherogenic influence of PUFA. Furthermore, there is considerable disparity between the effects of n-6 and n-3 PUFA on LDL levels despite the fact that highly unsaturated n-3 PUFA would be expected to confer even greater susceptibility to oxidation on LDL, thus enhancing its removal.

\section{MONOUNSATURATED FATTY ACIDS OF THE N-9 SERIES}

While information on the effects of dietary MUFA on LDL subclasses is sparse, minimal effects on LDL heterogeneity could be predicted, given the apparent lack of evidence for a TG lowering influence of MUFA. A comparative study of the effects of n-6 PUFA $v$. MUFA showed there to be no differences in the concentrations of either large or small LDL between these two diets (Dreon et al. 1990). This finding is in contrast to the moderate LDL cholesterol lowering property of MUFA, the degree of which is often compared to that of n-6 PUFA (Ginsberg et al. 1990; Wardlaw \& Snook, 1990; Chan et al. 1991; Wahrburg et al. 1992; Nydahl et al. 1994a,b). The concomitant reduction in apo B levels after the consumption of a MUFA-enriched diet suggests that the decrease in LDL cholesterol may arise from either an increased clearance or decreased synthesis of LDL particles rather than changes in their cholesterol content (Chan et al. 1991). Grundy \& Denke (1990) suggested that MUFA and PUFA may allow the natural expression of LDL receptor activity, if this is the main variant, whereas long chain SFA have a suppressive effect.

\section{MUFA and susceptibility of $L D L$ to oxidative modification}

One of the protective effects of dietary MUFA on an ALP is thought to be the relatively lower susceptibility of oleic acid-rich cholesteryl esters, phospholipids and TG to lipid peroxidation and thus the oxidative modification of LDL as compared to n-3 and n-6 
PUFA. As discussed, this protective effect seems to be confined to small dense LDL (Reaven et al. 1994) which is the LDL subclass that expresses increased susceptibility to oxidation in vitro (de Graaf et al. 1991; Tribble et al. 1992). When oxidative stress was assessed in the Jerusalem Nutrition Study (Berry et al. 1991) it was found that LDL isolated after a PUFA enriched diet contained significantly increased levels of lipid peroxides as compared to LDL isolated after a MUFA enriched diet. In addition, LDL isolated from mildly hypercholesterolaemic subjects on a MUFA-rich diet was found to be less susceptible to copper mediated oxidation and lipid peroxide formation, and less susceptible to LDL-protein modification than the LDL isolated from the same subjects on a n-6 PUFA diet (Reaven et al. 1993b). Although compositional changes occurred in the HDL, this lipoprotein retained its powerful capacity to inhibit the oxidative modification of LDL in vitro.

\section{DIETARY EFFECTS ON HDL AND HDL SUBCLASSES}

\section{SATURATED FATTY ACIDS}

The relative cholesterol raising potencies of the different saturates and the mechanisms by which they are controlled lie beyond the scope of this review. However, dietary saturates do seem to exert differential effects on HDL. Myristic acid (C:14) has been shown to raise $\mathrm{HDL}$ (as large cholesteryl ester-rich $\mathrm{HDL}_{2}$ ) to a greater extent than either lauric $(\mathrm{C}: 12)$ or palmitic acid (C:16) (Zock et al. 1994). High fat diets in general are known to stimulate the synthesis of apoprotein A-I in the gut (Shepherd et al. 1978). This effect in the presence of efficient LPL mediated lipolysis and sufficient esterification capacity would facilitate the synthesis of nascent $\mathrm{HDL}$ and conversion of $\mathrm{HDL}_{3}$ to cholesterol-rich $\mathrm{HDL}_{2}$, processes which, through association with reverse cholesterol transport, are considered beneficial.

\section{Effects on CETP activity}

High fat diets are reported to increase the activity of CETP and CETP mRNA levels (Tall, 1993). Since CETP is intimately involved in the remodelling of LDL and HDL subclasses, it has been proposed that the effects of dietary SFA on these lipoprotein subclasses are mediated through this lipid transfer protein. The stimulatory effect of a high fat diet on CETP activity has been ascribed to the dietary cholesterol component rather than the SFA (Tall, 1993), though this is not the view held by others who report a stimulation of CETP mediated redistribution of HDL particle size and transfer of cholesteryl esters between $\mathrm{HDL}_{3}$ and LDL by medium and long chain SFA (Lagrost \& Barter, 1992). Whatever the mechanism, the increases in VLDL and LDL associated with dietary SFA will almost certainly negate the benefits of raising HDL levels through a stimulation of CETP.

\section{PUFA OF THE N-3 AND N-6 SERIES}

Decreases in the concentration of HDL in response to dietary n-6 PUFA in excess of about $10 \%$ of total calories is a reasonably well established finding that may be attributed to a fall in the synthesis of apo A-I (Shepherd et al. 1978). Intakes below this level seem to have no significant effects. In reviewing the impact of dietary n-3 PUFA on HDL, Schmitz \& Lackner (1993) suggest that the outcome depends upon the lipoprotein phenotype and the amount of n-3 PUFA ingested. If this is the case, it is predictable that subjects with raised TG levels may be more responsive to n-3 PUFA in terms of reciprocal changes in HDL and TG in both fasting and postprandial plasma. A decrease in the transfer of cholesteryl esters 
from HDL to VLDL and LDL, as reported by Bagdade et al. (1992), would favour an accumulation of large $\mathrm{HDL}_{2}$ and thus $\mathrm{HDL}$ cholesterol, as previously found in healthy volunteers on fish oil supplements (Blonk et al. 1990; Childs et al. 1990). Similar diets in hypertriglyceridaemic subjects are reported to increase the smaller $\mathrm{HDL}_{3}$ subclass (Deck \& Radack, 1989), which is in agreement with Schmidt et al. (1993). While the origin of these effects is not clear, decreases in the activity of lecithin-cholesterol acyl transferase (EC 2.3.1.43), due to polyunsaturation of phosphatidylcholine, and CETP have been implicated.

\section{MONOUNSATURATED FATTY ACIDS OF THE N-9 SERIES}

Views concerning the influence of MUFA on HDL cholesterol levels are controversial. A commonly held view is that the isocaloric replacement of SFA with MUFA does not decrease HDL and may even increase its levels (Grundy, 1989; Grundy \& Denke 1990; Spiller et al. 1992; Lichtenstein et al. 1993). This is also supported by the recent findings of Mata and co-workers $(1992 a, b)$ who observed higher HDL cholesterol and apo A-I levels after MUFA-rich diets compared to PUFA-rich diets in both men and women. Nevertheless, numerous studies have reported either no effects of dietary MUFA on HDL cholesterol and/or apo A-I (Wardlaw \& Snook, 1990; Kris-Etherton et al. 1993), or even decreases in this lipoprotein relative to SFA-rich diets (Foley et al. 1992; Valsta et al. 1992; Nydahl et al. 1994b). It is interesting to note that elevations in apo A-I have been accompanied by reductions in HDL cholesterol (Wahrburg et al. 1992). This finding might suggest that under certain circumstances dietary MUFA promotes the synthesis of new HDL particles. Valsta et al. (1992) suggested that dietary MUFA, provided in the form of rapeseed oil, may result in a more favourable ratio of $\mathrm{HDL}_{2}-\mathrm{C}$ to $\mathrm{LDL}-\mathrm{C}$ and apo $\mathrm{A}-\mathrm{I}$ to apo $B$ than n-6 PUFA. This effect was, however, attributed to greater decreases in LDL concentrations rather than $\mathrm{HDL}$. In cell culture studies, $\mathrm{HDL}_{3}$ obtained from women on a MUFA-rich diet induced the greatest efflux of cholesterol from fibroblasts, reduced the content of intracellular cholesterol and enhanced LDL degradation, when compared with HDL isolated from subjects fed SFA, n-6 and n-3 PUFA-rich diets (Sola et al. 1993).

Incubations of HDL in vitro with either VLDL or LDL that included sodium oleate in the media as the sole source of fatty acid did not affect HDL particle size. When CETP was included in the media, HDL particle size was reduced (Barter et al. 1990). However, when diet induced alterations of CETP activity were investigated in vivo, a significant decrease following a MUFA-rich and a non-significant decrease following a PUFA-rich diet was observed in CETP activity when compared to a control SFA-rich diet (Groener et al. 1991). It could be concluded from these studies that while a MUFA-rich diet may reduce CETP activity in vivo this is inconsistent with the reduction of HDL particle size found in vitro and the postulated role of CETP in neutral liquid exchange (Fig. 3). Further research is clearly necessary to verify the effects of dietary MUFA on HDL subclasses and to elucidate its underlying mechanisms of action.

\section{TRANS FATTY ACIDS}

Although trans fatty acids are considered hypercholesterolaemic compared to their cis isomers and produce equivalent effects on LDL levels to that of SFA, they are reported to decrease HDL levels and, as such, behave differently to the long chain SFA. These effects were found to be either as pronounced as those of long chain SFA (Judd et al. 1994) or even greater than them (Mensink \& Katan, 1990). Raised CETP activity has been reported in response to the trans isomer of oleic acid, namely elaidic acid $v$. its cis isomer (Abbey \& Nestel, 1994). While CETP activity was significantly correlated with HDL levels in subjects 
consuming the diet rich in elaidic acid, there was no significant difference in mean HDL cholesterol concentrations between diets rich in oleic and elaidic acids. Lagrost (1992) also found that elaidic acid increased CETP activity, the CETP mediated redistribution of cholesteryl esters and net mass transfer of cholesterol from $\mathrm{HDL}_{3}$ to LDL. Overall, these findings imply that trans fatty acids produce a shift in the distribution of HDL particle size towards smaller particles through increased lipid transfer that is independent of TG levels.

\section{DIET-GENE INTERACTIONS AND INSULIN RESISTANCE}

\section{DIET-GENE INTERACTIONS}

Diet-gene interactions are believed to underlie not only the significant variations in the response of plasma lipids and lipoproteins to dietary fatty acids but also the development of an ALP. One of the best examples of a common, diet-gene interaction is provided by the apoprotein E4 polymorphism. Several groups have shown that PUFA enriched diets induced significantly greater reductions in total plasma and LDL cholesterol in individuals who possess the apo $\epsilon 4$ allele (Tikkanen et al. 1990; Manttari et al. 1991). Although these studies showed no associations between apo E phenotype and changes in either TG or HDL, the response of LDL cholesterol to the substitution of saturated fat with carbohydrate has been linked to a more marked reduction of larger, relatively cholesterolrich LDL within subjects expressing the 64 allele (Dreon $e t$ al. 1995). While a review of the interactions between diet and genes which encode the metabolic determinants of the ALP is urgently required, the nature of these genes and how they interact with dietary factors is still unclear. Molecular studies on familial combined hyperlipidaemia, a condition characterized by patterns of lipoprotein heterogeneity similar to that of an ALP, have provided a significant insight into the nature of candidate, ALP genes. Examples of such genes include: (i) $L P L$ gene. The issue of whether dietary fatty acids, and in particular, long chain n-3 PUFA, can upregulate LPL gene expression is contentious and is likely to remain so until the activity and gene expression of LPL is measured accurately in specific human tissues; (ii) apo AI-CII-AIV gene cluster. Dietary induced variation in apo A-I levels have been attributed to variation in this gene cluster by $\mathrm{Xu}$ et al. (1990). In addition, apo A-IV levels are positively associated with dietary fat intake (Weinberg et al. 1990); (iii) $A T H S$ gene. Linkage of small dense LDL (pattern B) to the LDL receptor gene has been recently confirmed (Rotter et al. 1994). There were earlier but as yet unconfirmed reports that the expression of this genetic linkage was modified by levels of dietary fat and carbohydrate (Nishina et al. 1992). Future knowledge of the way in which these and other genetic loci such as HL and CETP influence dietary responsiveness and the development of the ALP will assist greatly in the formulation and targeting of dietary recommendations towards genetically susceptible groups.

\section{INSULIN RESISTANCE}

The effects of gene-diet interactions on the ALP might well be mediated through mechanisms of insulin resistance. The resistance of peripheral tissues to the action of insulin has been attributed to the degree of saturation of fatty acids in the phospholipids of muscle membranes (Storlien et al. 1991). This is thought to be regulated by interactions between genetically controlled enzyme systems responsible for the elongation and desaturation of fatty acids, and dietary fatty acids. In rats, dietary SFA, n-6 PUFA and MUFA have all been shown to promote insulin resistance via this mechanism, whereas long chain n-3 PUFA prevent its development. Moreover, in human skeletal muscle these latter fatty acids 
were shown to improve insulin action (Borkman et al. 1993). In view of the widespread effects of improved insulin sensitivity on lipid metabolism and possibly independent effects of n-3 PUFA on LPL gene expression, it is reasonable to speculate that in addition to inappropriate high intakes of fat and physical inactivity, the prevalence of the ALP is a result of a dietary deficiency in long chain n-3 PUFA derived from fish oils that has developed over the past forty years. This idea would offer the most rational approach to future intervention studies designed to address the influence of dietary fatty acids on CHD risk mediated through the ALP.

\section{CONCLUSIONS}

The ALP is a relatively new concept which describes a common collection of abnormalities in LDL and HDL that predispose apparently healthy individuals to increased CHD risk. As a likely product of insulin resistance, the ALP represents a dyslipidaemia of TG metabolism. It has a genetic origin but can be influenced, possibly through gene expression, by dietary factors and should therefore be regarded as a modifiable risk factor for CHD. Despite significant advance in our understanding of the genetic and metabolic basis of an ALP, few studies have addressed the influence of dietary fatty acids on the ALP as a distinct dyslipidaemia. In the absence of specific research material, much can be learnt from the effects of dietary fatty acids on determinants of lipoprotein heterogeneity, the most important of which are the TG-rich lipoproteins of hepatic and dietary origin. In this respect, dietary SFA and n-6 PUFA have minimal effects relative to the long chain $n-3$ PUFA which clearly harbour the greatest potential to correct the abnormalities of an ALP and may even offer longer term benefits by increasing insulin sensitivity through gene-diet interactions. In addition, the ability of dietary MUFA to confer protection against the oxidative modification of LDL is particularly relevant in the case of the ALP, given its low levels of HDL and predominance of oxidatively susceptible small dense LDL.

\section{REFERENCES}

Abbey, M. \& Nestel, P. J. (1994). Plasma cholesteryl ester transfer protein activity is increased when trans-elaidic acid is substituted for cis-oleic acid in the diet. Atherosclerosis 106, 99-107.

Austin, M. A. (1991). Plasma triglyceride and coronary heart disease. Arteriosclerosis and Thrombosis 11, $2-14$. Austin, M. A. (1993). Genetics of low-density lipoprotein subclasses. Current Opinion in Lipidology 4, $125-132$. Austin, M. A., Breslow, J. L., Hennekens, C. H., Buring, J. E., Willett, W. C. \& Krauss, R. M. (1988). Low density lipoprotein subclass patterns and risk of myocardial infarction. Journal of the American Medical Association 260, 1917-1921.

Austin, M. A., King, M.-C., Vranizan, K. M. \& Krauss, R. M. (1990). Atherogenic lipoprotein phenotype. A proposed genetic marker for coronary heart disease risk. Circulation 82, 495-506.

Austin, M. A. \& Krauss, R. M. (1986). Genetic control of low density lipoprotein subclasses. Lancet ii, 592-594.

Bagdade, J. D., Ritter, M. C., Davidson, M. \& Subbaiah, P. V. (1992). Effect of marine lipids on cholesterol ester transfer and lipoprotein composition in patients with hypercholesterolemia. Arteriosclerosis and Thrombosis 12, $1146-1152$.

Ballantyne, F., Clark, R. S., Simpson, H. S. \& Ballantyne, D. (1982). High density and low density lipoprotein subfractions in survivors of myocardial infarction. Metabolism 31, $433-437$.

Barter, P. J., Chang, L. B. F., Newnham, H. H., Rye, K.-A. \& Rajaram, O. V. (1990). The interaction of cholesteryl ester transfer protein and unesterified fatty acids promotes a reduction in the particle size of highdensity lipoproteins. Biochimica et Biophysica Acta 1045, 81-89.

Beltz, W. F., Young, S. G. \& Witztum, J. L. (1987). Heterogeneity in low density lipoprotein metabolism. In Proceedings of the Workshop on Lipoprotein Heterogeneity, pp. 215-236 [K. Lippel, editor]. Bethesda, MD: National Institutes of Health.

Berry, E. M., Eisenberg, S., Haratz, D., Friedlander, Y, Norman, Y., Kaufmann, N. A. \& Stein, Y. (1991). Effects of diets rich in monounsaturated fatty acids on plasma lipoproteins - the Jerusalem Nutrition Study: high MUFAs vs high PUFAs. American Journal of Clinical Nutrition 53, 899-907. 
Blonk, M. C., Bilo, H. J. G., Nauta, J. J. P., Popp-Snijders, C., Mulder, C. \& Donker, A. J. M. (1990). Doseresponse effects of fish-oil supplementation in healthy volunteers. American Journal of Clinical Nutrition 52 , 120-127.

Borkman, M., Storlien, L. H., Pan, D. A., Jenkins, A. B., Chisholm, D. J. \& Campbell, L. V. (1993). The relation between insulin sensitivity and the fatty acid composition of skeletal muscle phospholipids. New England Journal of Medicine 328, 238-244.

Brouwer, C. B., de Bruin, T. W. A., Jansen, H. \& Erkelens, D. W. (1993). Different clearance of intravenously administered olive oil and soybean-oil emulsions: role of hepatic lipase. American Journal of Clinical Nutrition 57, 533-539.

Brown, A. J. \& Roberts, D. C. K. (1991). Moderate fish oil intake improves lipemic response to a standard fat meal. A study in 25 healthy men. Arteriosclerosis and Thrombosis 11, 457-466.

Brunzell, J. D., Hazzard, W. R., Porte, D. \& Bierman, E. L. (1973). Evidence for a common, saturable, triglyceride removal mechanism for chylomicrons and very low density lipoproteins in man. Journal of Clinical Investigation 52, 1578-1585.

Camejo, G., Hurt-Camejo, E. \& Bondjers, G. (1990). Effect of proteoglycans on lipoprotein-cell interactions: possible contribution to atherogenesis. Current Opinion in Lipidology 1, 431-436.

Campos, H., Willett, W. C., Peterson, R. M., Siles, X., Bailey, S. M., Wilson, P. W. F., Posner, B. M., Ordovas, J. M. \& Schaefer, E. J. (1991). Nutrient intake comparisons between Framingham and rural and urban Puriscal, Costa Rica. Associations with lipoproteins, apolipoproteins, and low density lipoprotein particle size. Arteriosclerosis and Thrombosis 11, 1089-1099.

Caslake, M. J., Packard, C. J., Griffin, B. A., Gaw, A. \& Shepherd, J. (1994). LDL subfraction metabolism in young healthy males. Atherosclerosis 109, 122 (Abstract).

Castelli, W. P. (1994). Does epidemiology define the individual at risk? Atherosclerosis 109, 92 (Abstract).

Castelli, W. P., Doyle, J. T., Gordon, T., Hames, C. G., Hjortland, M. C., Hulley, S. B., Kagan, A. \& Zukel, W. J. (1977). HDL cholesterol and other lipids in coronary heart disease: The Cooperative Lipoprotein Phenotyping Study. Circulation 55, 767-772.

Chan, J. K., Bruce, V. M. \& McDonald, B. E. (1991). Dietary $\alpha$-linolenic acid is as effective as oleic acid and linoleic acid in lowering blood cholesterol in normolipidemic men. American Journal of Clinical Nutrition 53, 1230-1234.

Chen, Y.-D. I., Swami, S., Skowronski, R., Coulston, A. \& Reaven, G. M. (1993). Differences in postprandial lipemia between patients with normal glucose tolerance and noninsulin-dependent diabetes mellitus. Journal of Clinical Endocrinology and Metabolism 76, 172-177.

Childs, M. T., Dorsett, C. S., King, I. B., Ostrander, J. G. \& Yamanaka, W. K. (1990). Effects of shellfish consumption on lipoproteins in normolipidemic men. American Journal of Clinical Nutrition 41, $1020-1027$.

Connor, W. E., DeFrancesco, C. A. \& Connor, S. L. (1993). N-3 fatty acids from fish oil. Effects on plasma lipoproteins and hypertriglyceridemic patients. Annals of the New York Academy of Sciences 683, 16-34.

Contacos, C., Barter, P. J. \& Sullivan, D. R. (1993). Effect of pravastatin and $\omega-3$ fatty acids on plasma lipids and lipoproteins in patients with combined hyperlipidemia. Arteriosclerosis and Thrombosis 13, 1755-1762.

Cortese, C., Levy, Y., Janus, E. D., Turner, P. R., Rao, S. N., Miller, N. E. \& Lewis, B. (1983). Modes of action of lipid-lowering diets in man: studies of apolipoprotein B kinetics in relation to fat consumption and dietary fatty acid composition. European Journal of Clinical Investigation 13, 79-85.

de Bruin, T. W. A., Brouwer, C. B., Trip, M. L. S., Jansen, H. \& Erkelens, D. W. (1993). Different postprandial metabolism of olive oil and soybean oil: a possible mechanism of the high-density lipoprotein conserving effect of olive oil. American Journal of Clinical Nutrition 58, 477-483.

de Graaf, J., Hak-Lemmers, H. L. M., Hectors, M. P. C., Demacker, P. N. M., Hendricks, J. C. M. \& Stalenhoef, A. F. H. (1991). Enhanced susceptibility to in vitro oxidation of the dense low density lipoprotein subfraction in healthy subjects. Arteriosclerosis and Thrombosis 11, 298-306.

Deck, C. \& Radack, K. (1989). Effects of modest doses of omega-3 fatty acids on lipids and lipoproteins in hypertriglyceridemic subjects. Archives of Internal Medicine 149, 1857-1862.

Demacker, P. N. M., Reijnen, I. G. M., Katan, M. B., Stuyt, P. M. J. \& Stalenhoef, A. F. H. (1991). Increased removal of remnants of triglyceride-rich lipoproteins on a diet rich in polyunsaturated fatty acids. European Journal of Clinical Investigation 21, 197-203.

Department of Health (1994). Nutritional aspects of cardiovascular disease. Report on Health and Social Subjects no. 46. London: HMSO.

Despres, J. P. \& Marette, A. (1994). Relation of components of insulin resistance syndrome to coronary heart disease risk. Current Opinion in Lipidology 5, 274-289.

Dixon, J. L. \& Ginsberg, H. N. (1993). Regulation of hepatic secretion of apolipoprotein B-containing lipoproteins: information obtained from cultured cells. Journal of Lipid Research 34, 167-179.

Dreon, D. M., Fernstrom, H. A., Miller, B. \& Krauss, R. M. (1994). Low-density lipoprotein subclass patterns and lipoprotein response to a reduced-fat diet in men. FASEB Journal 8, 121-126.

Dreon, D. M., Fernstrom, H. A., Miller, B. \& Krauss, R. M. (1995). Apolipoprotein E isoform phenotype and LDL subclass response to a reduced fat diet. Arteriosclerosis, Thrombosis, and Vascular Biology 15, $105-111$.

Dreon, D. M., Vranizan, K. M., Krauss, R. M., Austin, M. A. \& Wood, P. D. (1990). The effects of polyunsaturated fat vs monounsaturated fat on plasma lipoproteins. Journal of the American Medical Association 263, 2462-2466. 
Dufaux, B., Assmann, G. \& Hollmann, W. (1982). Plasma lipoproteins and physical activity: a review. International Journal of Sports Medicine 3, 123-136.

Durrington, P. N. (1989). Diet. Hyperlipidaemia. Diagnosis and Management, pp. 166-194. London: Butterworth.

Ellsworth, J. L., Cooper, A. D. \& Kraemer, F. B. (1986). Evidence that chylomicron remnants and $\beta$-VLDL are transported by the same receptor pathway in $\mathbf{J 7 7 4}$ murine macrophage-derived cells. Journal of Lipid Research 27, 1062-1072.

Fernandez, M. L., Abdel-Fattah, G. \& McNamara, D. J. (1993). Dietary fat saturation modifies the metabolism of LDL subfractions in guinea pigs. Arteriosclerosis and Thrombosis 13, 1418-1428.

Fisher, R. M., Coppack, S. W., Gibbons, G. F. \& Frayn, K. N. (1993). Postprandial VLDL subfraction metabolism in normal and obese subjects. International Journal of Obesity 17, 263-269.

Fisher, W. R., Zech, L. A., Bardalaye, P., Warmke, G. \& Berman, M. (1980). The metabolism of apolipoprotein $B$ in subjects with hypertriglyceridemia and polydisperse LDL. Journal of Lipid Research 21, 760-774.

Foley, M., Ball, M., Chisholm, A., Duncan, A., Spears, G. \& Mann, J. (1992). Should mono- or poly-unsaturated fats replace saturated fat in the diet? European Journal of Clinical Nutrition 46, 429-436.

Franceschini, G., Bernini, F., Michelagnoli, S., Bellosta, S., Vaccarino, V., Fumagalli, R. \& Sirtori, C. R. (1990). Lipoprotein changes and increased affinity of LDL for their receptors after acipimox treatment in hypertriglyceridemia. Atherosclerosis 81, 41-49.

Frayn, K. N. (1993). Insulin resistance and lipid metabolism. Current Opinion in Lipidology 4, $197-204$.

Friday, K. E., Failor, R. A., Childs, M. T. \& Bierman, E. L. (1991). Effects of n-3 and n-6 fatty acid-enriched diets on plasma lipoproteins and apolipoproteins in heterozygous familial hypercholesterolemia. Arteriosclerosis and Thrombosis 11, 47-54.

Gaw, A., Packard, C. J., Lindsay, G. M., Griffin, B. A., Caslake, M. J., Lorimer, A. R. \& Shepherd, J. (1995). Overproduction of small very low density lipoproteins $\left(S_{1} 20-60\right)$ in moderate hypercholesterolemia: relationships between apolipoprotein B kinetics and plasma lipoproteins. Journal of Lipid Research 36, $158-171$.

Gerhard, G. T., Patton, B. D., Linquist, S. A. \& Wander, R. C. (1991). Comparison of three species of dietary fish: effects on serum concentrations of low-density-lipoprotein cholesterol and apolipoprotein in normotriglyceridemic subjects. American Journal of Clinical Nutrition 54, 334-339.

Gianturco, S. H. \& Bradley, W. A. (1991). A cellular basis for the atherogenicity of triglyceride-rich lipoproteins. Atherosclerosis Reviews 22, 9-14.

Ginsberg, H. N., Barr, S. L., Gilbert, A., Karmally, W., Deckelbaum, R., Kaplan, K., Ramakrishnan, R., Holleran, S. \& Dell, R. B. (1990). Reduction of plasma cholesterol levels in normal men on an American Heart Association Step 1 diet or a Step 1 diet with added monounsaturated fat. New England Journal of Medicine 322, 574-579.

Griffin, B. A., Caslake, M. J., Gaw, A., Yip, B., Packard, C. J. \& Shepherd, J. (1992). Effects of cholestyramine and acipimox on subfractions of plasma low density lipoprotein. Studies in normolipidaemic and hypercholesterolaemic subjects. European Journal of Clinical Investigation 22, 383-390.

Griffin, B. A., Freeman, D. J., Tait, G. W., Thomson, J., Caslake, M. J., Packard, C. J. \& Shepherd, J. (1994). Role of plasma triglyceride in the regulation of plasma low density lipoprotein (LDL) subfractions: relative contribution of small, dense LDL to coronary heart disease risk. Atherosclerosis 106, 241-253.

Groener, J. E. M., van Ramshorst, E. M., Katan, M. B., Mensink, R. P. \& van Tol, A. (1991). Diet-induced alteration in the activity of plasma lipid transfer protein in normolipidemic human subjects. Atherosclerosis $\mathbf{8 7}$, 221-226.

Groot. P. H. E., van Stiphout, W. A. H. J., Krauss, X. H., Jensen, H., van Tol, A., van Ramshorst, E., Chin-On, S., Hofman, A., Cresswell, S. R. \& Hanekes, L. (1991). Postprandial lipoprotein metabolism in normolipidemic men with and without coronary artery disease. Arteriosclerosis and Thrombosis 11, 653-662.

Grundy, S. M. (1989). Monounsaturated fatty acids and cholesterol metabolism: implications for dietary recommendations. Journal of Nutrition 119, $529-533$.

Grundy, S. M. \& Denke, M. A. (1990). Dietary influences on serum lipids and lipoproteins. Journal of Lipid Research 31, $1149-1172$.

Hamsten, A., Walldius, G., Dahlén, G., Johansson, B. \& de Faire, U. (1986). Serum lipoproteins and apolipoproteins in young male survivors of myocardial infarction. Atherosclerosis 59, 223-235.

Hänninen, O. O., Ågren, J. J., Laitinen, M. V., Jääskeläinen, I. O. \& Penttilä, I. M. (I989). Dose-response relationships in blood lipids during moderate freshwater fish diet. Annals of Medicine 21, 203-207.

Harris, W. S. (1989). Fish oils and plasma lipid and lipoprotein metabolism in humans: a critical review. Journal of Lipid Research 30, 785-807.

Harris, W. S., Connor, W. E., Alam, N. \& Illingworth, D. R. (1988a). Reduction of postprandial triglyceridemia in humans by dietary n-3 fatty acids. Journal of Lipid Research 29, 1451-1460.

Harris, W. S., Dujovne, C. A., Zucker, M. \& Johnson, B. (1988b). Effects of a low saturated fat, low cholesterol fish oil supplement in hypertriglyceridemic patients. A placebo-controlled trial. Annals of Internal Medicine 109, 465-470.

Harris, W. S. \& Muzio, F. (1993). Fish oil reduces postprandial triglyceride concentrations without accelerating lipid-emulsion removal rates. American Journal of Clinical Nutrition 58, 68-74.

Herzberg, G. R. (1991). Dietary regulation of fatty acid and triglyceride metabolism. Canadian Journal of Physiology and Pharmacology 69, 1637-1647. 
Homma, Y., Ohshima, K., Yamaguchi, H., Nakamura, H., Araki, G. \& Goto, Y. (1991). Effects of eicosapentaenoic acid on plasma lipoprotein subfractions and activities of lecithin: cholesterol acyltransferase and lipid transfer protein. Atherosclerosis 91, 145-153.

Huff, M. W. \& Telford, D. E. (1989). Dietary fish oil increases conversion of very low density lipoprotein apoprotein B to low density lipoprotein. Arteriosclerosis 9, 58-66.

Illingworth, D. R. \& Schmidt, E. B. (1993). The influence of dietary fatty acids on plasma lipids and lipoproteins. Annals of the New York Academy of Sciences 676, 60-69.

Illingworth, D. R., Sundberg, E. E., Becker, N., Connor, W. E. \& Alaupovic, P. (1981). Influence of saturated, monounsaturated and w6-PUFA on LDL metabolism in man. Arteriosclerosis 1, 380.

Isherwood, S. G., Williams, C. M., Griffin, B. A. \& Gould, B. J. (1995). Chylomicron remnants are present in the low density lipoprotein fraction $\left(\mathrm{S}_{\mathrm{f}} \mathrm{0}-12\right)$ as detected by a specific antibody to apolipoprotein B-48. Proceedings of the 64th Congress of the European Atherosclerosis Society, Utrecht, Netherlands, abstract.

Jackson, R. L., McLean, L. R. \& Demel, R. A. (1987). Mechanism of action of lipoprotein lipase and hepatic triglyceride lipase. American Heart Journal 113, 551-554.

James, R. W. \& Pometta, D. (1991). The distribution profiles of very low density and low density lipoproteins in poorly-controlled male, Type 2 (non-insulin dependent) diabetic patients. Diabetologia 34, 246-252.

Jiang, Z. \& Sim, J. S. (1993). Consumption of n-3 polyunsaturated-enriched eggs and changes in plasma lipids of human subjects. Nutrition 9, 561-562.

Judd, J. T., Clevidence, B. A., Muesing, R. A., Wittes, J., Sunkin, M. E. \& Podczasy, J. J. (1994). Dietary trans fatty acids: effects on plasma lipids and lipoproteins of healthy men and women. American Journal Clinical Nutrition 59, 861-868.

Kris-Etherton, P. M., Derr, J., Mitchell, D. C., Mustad, V. A., Russell, M. E., McDonnell, E. T., Salabsky, D. \& Pearson, T. A. (1993). The role of fatty acid saturation on plasma lipids, lipoproteins, and apolipoproteins. I. Effects of whole food diets high in cocoa butter, olive oil, soybean oil, dairy butter, and milk chocolate on the plasma lipids of young men. Metabolism, 42, 121-129.

Lagrost, L. (1992). Differential effects of cis and trans fatty acid isomers, oleic and elaidic acids, on the cholesterol ester transfer protein activity. Biochimica et Biophysica Acta 1124, $159-162$.

Lagrost, L. \& Barter, P. J. (1992). Cholesteryl ester transfer protein promotes the association of HDL apolipoproteins A-I and A-II with LDL: potentiation by oleic acid. Biochimica et Biophysica Acta 1127, 255-262.

Lagrost, L., Gambert, P., Dangremont, V., Athias, A. \& Lallemant, C. (1990). Role of cholesteryl ester transfer protein (CETP) in the HDL conversion process as evidenced by using anti-CETP monoclonal antibodies. Journal of Lipid Research 31, 1569-1575.

Lagrost, L., Gandjini, H., Athias, A., Dangremont, V., Lallemant, C. \& Gambert, P. (1993). Influence of plasma cholesteryl ester transfer activity on the LDL and HDL distribution profiles in normolipidemic subjects. Arteriosclerosis and Thrombosis 13, 815-825.

Levine, P. H., Fisher, M., Schneider, P. B., Whitten, R. H., Weiner, B. H., Ockene, I. S., Johnson, B. F., Johnson, M. H., Doyle, E. M., Riendeau, P. A. \& Hoogasian, J. J. (1989). Dietary supplementation with omega-3 fatty acids prolongs platelet survival in hyperlipidemic patients with atherosclerosis. Archives of Internal Medicine 149, 1113-1116.

Levy, E., Roy, C. C., Goldstein, R., Bar-On, H. \& Ziv, E. (1991). Metabolic fate of chylomicrons obtained from rats maintained on diets varying in fatty acid composition. Journal of the American College of Nutrition 10 , 69-78.

Lewis, G. F., O'Meara, N. M., Soltys, P. A., Blackman, J. D., Iverius, P. H., Pugh, W. L., Getz, G. S. \& Polonsky, K. S. (1991). Fasting hypertriglyceridemia in noninsulin-dependent diabetes mellitus is an important predictor of postprandial lipid and lipoprotein abnormalities. Journal of Clinical Endocrinology and Metabolism 72, 934-944.

Lichtenstein, A. H., Ausman, L. M., Carrasco, W., Jenner, J. L., Gualtieri, L. J., Goldin, B. R., Ordovas, J. M. \& Schaefer, E. J. (1993). Effects of canola, corn, and olive oils on fasting and postprandial plasma lipoproteins in humans as part of a National Cholesterol Education Program Step 2 diet. Arteriosclerosis and Thrombosis 13, 1533-1542.

Manninen, V., Tenkanen, L., Huttunen, J. K. \& Frick, M. H. (1991). The prognostic value of triglycerides in coronary heart disease. Findings from the Helsinki Heart Study. Atherosclerosis Reviews 22, 71-73.

Manttari, M., Koskinen, P., Ehnholm, C., Huttunen, J. K. \& Manninen, V. (1991). Apolipoprotein E polymorphism influences the serum cholesterol response to dietary intervention. Metabolism 40, $217-221$.

Marsh, J. B., Topping, D. L. \& Nestel, P. J. (1987). Comparative effects of dietary fish oil and carbohydrate on plasma lipids and hepatic activities of phosphatidate phosphohydrolase, diacylglycerol acyltransferase and neutral lipase activities in the rat. Biochimica et Biophysica Acta 922, 239-243.

Mata, P., Alvarez-Sala, L. A., Rubio, M. J., Nuño, J. \& de Oya, M. (1992a). Effects of long-term monounsaturated- vs polyunsaturated-enriched diets on lipoproteins in healthy men and women. American Journal of Clinical Nutrition 55, 846-850.

Mata, P., Garrido, J. A., Ordovas, J. M., Blazquez, E., Alvarez-Sala, L. A., Rubio, M. J., Alonso, R. \& de Oya, M. (1992b). Effect of dietary monounsaturated fatty acids on plasma lipoproteins and apolipoproteins in women. American Journal of Clinical Nutrition 56, 77-83. 
Mensink, R. P. \& Katan, M. B. (1990). Effect of dietary trans fatty acids on high-density and low-density lipoprotein cholesterol levels in healthy subjects. New England Journal of Medicine 323, 439-445.

Mensink, R. P. \& Katan, M. B. (1993). Trans monounsaturated fatty acids in nutrition and their impact on serum lipoprotein levels in man. Progress in Lipid Research 32, 111-122.

Murphy, M. C., Zampelas, A., Puddicombe, S. M., Furlonger, N. P., Morgan, L. M. \& Williams, C. M. (1993). Pretranslational regulation of the expression of the lipoprotein lipase (EC 3.1.1.34) gene by dietary fatty acids in the rat. British Journal of Nutrition 70, 727-736.

Murthy, S., Albright, E., Mathur, S. N. \& Field, F. J. (1990). Effect of eicosapentaenoic acid on triacylglycerol transport in CaCo-2 cells. Biochimica et Biophysica Acta 1045, 147-155.

Nenseter, M. S., Rustan, A. C., Lund-Katz, S., Soyland, E., Maelandsmo, G., Phillips, M. C. \& Drevon, C. A. (1992). Effect of dietary supplementation with n-3 polyunsaturated fatty acids on physical properties and metabolism of low density lipoproteins in humans. Arteriosclerosis and Thrombosis 12, 369-379.

Nestel, P. J. (1986). Fish oil attenuates the cholesterol-induced rise in lipoprotein cholesterol. American Journal of Clinical Nutrition 43, 752-757.

Nestel, P. J., Connor, W. E., Reardon, M. F., Connor, S., Wong, S. \& Boston, R. (1984). Suppression by diets rich in fish oil of very low density lipoprotein production in man. Journal of Clinical Investigation 74, 82-89.

Nichols, A. V. \& Smith, L. (1965). Effect of very low density lipoproteins on lipid transfer in incubated serum. Journal of Clinical Investigation 6, 206-210.

Nicoll, A. \& Lewis, B. (1980). Evaluation of the roles of lipoprotein lipase and hepatic lipase in lipoprotein metabolism: in vivo and in vitro studies in man. European Journal of Clinical Investigation 10, 487-495.

Nigon, F., Lesnik, P., Rouis, M. \& Chapman, M. J. (1991). Discrete subspecies of human low density lipoproteins are heterogeneous in their interaction with the cellular LDL receptor. Journal of Lipid Research 32, $1741-1753$.

Nikkila, M., Solakivi, T., Lehtimaki, T., Koivula, T., Laippala, P. \& Astrom, B. (1994). Postprandial plasma lipoprotein changes in relation to apolipoprotein $\mathrm{E}$ phenotypes and low density lipoprotein size in men with and without coronary artery disease. Atherosclerosis 106, 149-157.

Nishina, P. M., Johnson, J. P., Naggert, J. K. \& Krauss, R. M. (1992). Linkage of atherogenic lipoprotein phenotype to the low density lipoprotein receptor locus on the short arm of chromosome 19. Proceedings of the National Academy of Sciences of the USA 89, 708-712.

Norum, K. R. (1992). Dietary fat and blood lipids. Nutrition Reviews 50 (4, II), 30-37.

Nozaki, S., Garg, A., Vega, G. L. \& Grundy, S. M. (1991). Postheparin lipolytic activity and plasma lipoprotein response to $\omega-3$ polyunsaturated fatty acids in patients with primary hypertriglyceridemia. American Journal of Clinical Nutrition 53, 638-642.

Nydahl, M., Gustafsson, I.-B., Öhrvall, M. \& Vessby, B. (1994a). Similar serum lipoprotein cholesterol concentrations in healthy subjects on diets enriched with rapeseed and with sunflower oil. European Journal Clinical Nutrition 48, 128-137.

Nydahl, M. C., Gustafsson, I. B. \& Vessby, B. (1994b). Lipid-lowering diets enriched with monounsaturated or polyunsaturated fatty acids but low in saturated fatty acids have similar effects on serum lipid concentrations in hyperlipidemic patients. American Journal of Clinical Nutrition 59, 115-122.

O'Meara, N. M., Lewis, G. F., Cabana, V. G., Iverius, P. H., Getz, G. S. \& Polonsky, K. S. (1992). Role of basal triglyceride and high density lipoprotein in determination of postprandial lipid and lipoprotein responses. Journal of Clinical Endocrinology \& Metabolism 75, 465-471.

Patsch, J. R., Meisenböck, G., Hopferwieser, T., Muhlberger, V., Knapp, E., Dunn, J. K., Gotto, A. M. \& Patsch, W. (1992). Relation of triglyceride metabolism and coronary artery disease. Studies in the postprandial state. Arteriosclerosis and Thrombosis 12, 1336-1345.

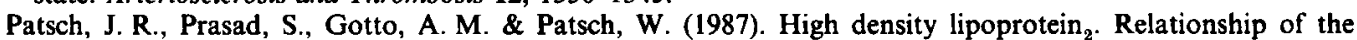
plasma levels of this lipoprotein species to its composition, to the magnitude of postprandial lipemia, and to the activities of lipoprotein lipase and hepatic lipase. Journal of Clinical Investigation 80, 341-347.

Patsch, W., Tamai, T. \& Schonfeld, G. (1983). Effect of fatty acids on lipid and apoprotein secretion and association in hepatocyte cultures. Journal of Clinical Investigation 72, 371-378.

Ramsay, L. E., Yeo, W. W. \& Jackson, P. R. (1991). Dietary reduction of serum cholesterol concentration: time to think again. British Medical Journal 303, 953-957.

Reaven, G. M. (1988). Role of insulin resistance in human disease. Diabetes 37, 1495-1607.

Reaven, G. M., Chen, Y.-D. I., Jeppesen, J., Maheux, P. \& Krauss, R. M. (1993a). Insulin resistance and hyperinsulinemia in individuals with small, dense, low density lipoprotein particles. Journal of Clinical Investigation 92, 141-146.

Reaven, P. D., Grasse, B. J. \& Tribble, D. L. (1994). Effects of linoleate-enriched and oleate-enriched diets in combination with $\alpha$-tocopherol on the susceptibility of LDL and LDL subfractions to oxidative modification in humans. Arteriosclerosis and Thrombosis 14, 557-566.

Reaven, P. D., Parthasarathy, S., Grasse, B. J., Miller, E., Steinberg, D. \& Witztum, J. L. (1993b). Effects of oleate-rich and linoleate-rich diets on the susceptibility of low density lipoprotein to oxidative modification in mildly hypercholesterolemic subjects. Journal of Clinical Investigation 91, 668-676.

Rotter, J. I., Bu, X., Cantor, R., Warden, C. H., Xia, Y. R., DeMeester, C., Teryua, S., Lokensgard, B., Daneshmand, A., Brown, J., Gray, R. J., Krauss, R. M. \& Lusis, A. J. (1994). Multilocus genetic determination of LDL particle size in coronary artery disease families. Clinical Research 42, 16A (Abstract). 
Rustan, A. C., Nossen, J. Ø., Christiansen, E. N. \& Drevon, C. A. (1988). Eicosapentaenoic acid reduces hepatic synthesis and secretion of triacylglycerol by decreasing the activity of acyl-coenzyme A:1,2-diacylglycerol acyltransferase. Journal of Lipid Research 29, 1417-1426.

Schmidt, E. B., Kristensen, S. D., De Caterina, R. \& Illingworth, D. R. (1993). The effects of n-3 fatty acids on plasma lipids and lipoproteins and other cardiovascular risk factors in patients with hyperlipidaemia. Atherosclerosis 103, 107-121.

Schmitz, G. \& Lackner, K. J. (1993). High-density lipoproteins and atherosclerosis. Current Opinion in Lipidology 4, 392-400.

Selby, J. V., Austin, M. A., Newman, B., Zhang, D., Quesenberry, C. P., Mayer, E. J. \& Krauss, R. M. (1993). Subclass phenotypes and the insulin resistance syndrome in women. Circulation 88, 381-387.

Senti, F. R. (Ed.) (1985). Health Aspects of Dietary Trans Fatty Acids. Bethesda, MD: Federation of American Societies for Experimental Biology.

Shepherd, J. \& Packard, C. J. (1987). Metabolic heterogeneity in very low density lipoproteins. American Heart Journal 113, 503-508.

Shepherd, J., Packard, C. J., Patsch, J. R., Gotto, A. M. \& Taunton, O. D. (1978). Effects of dietary polyunsaturated and saturated fat on the properties of high density lipoproteins and the metabolism of apolipoprotein A-I. Journal of Clinical Investigation 61, 1582-1592.

Sola, R., Motta, C., Maillé, M., Bargallo, M. T., Boisnier, C., Richard, J. L. \& Jacotot, B. (1993). Dietary monounsaturated fatty acids enhance cholesterol efflux from human fibroblasts. Relation to fluidity, phospholipid fatty acid composition, overall composition, and size of $\mathrm{HDL}_{3}$. Arteriosclerosis and Thrombosis 13, 958-966.

Spiller, G. A., Jenkins, D. J. A., Cragen, L. N., Gates, J. E., Bosello, O., Berra, K., Rudd, C., Stevenson, M. \& Superko, R. (1992). Effect of a diet high in monounsaturated fat from almonds on plasma cholesterol and lipoproteins. Journal of the American College of Nutrition 11, 126-130.

Storlien, L. H., Jenkins, A. B., Chisholm, D. J., Pascoe, W. S., Khouri, S. \& Kraegen, E. W. (1991). Influence of dietary fat composition on development of insulin resistance in rats. Relationship to muscle triglyceride and $\omega-3$ fatty acids in muscle phospholipid. Diabetes $40,280-289$.

Sullivan, D. R., Sanders, T. A. B., Trayner, I. M. \& Thompson, G. R. (1986). Paradoxical elevation of LDL apoprotein B levels in hypertriglyceridaemic patients and normal subjects ingesting fish oil. Atherosclerosis $\mathbf{6 1}$, 129-134.

Suzukawa, M., Abbey, M. \& Nestel, P. J. (1994). Effect of fish oil on LDL size, oxidizability and uptake by macrophages. Atherosclerosis 109, 73 (Abstract).

Swinkels, D. W., Hendriks, J. C. M., Demacker, P. N. M. \& Stalenhoef, A. F. H. (1990). Differences in metabolism of three low density lipoprotein subfractions in Hep G2 cells. Biochimica et Biophysica Acta 1047, 212-222.

Tall, A. R. (1993). Review. Plasma cholesteryl ester transfer protein. Journal of Lipid Research 34, $1255-1274$.

Tikkanen, M. J., Huttunen, J. K., Ehnholm, C. \& Pietinen, P. (1990). Apolipoprotein E homozygosity predisposes to serum cholesterol elevation during high fat diets. Arteriosclerosis 10, 285-288.

Tontonoz, P., Hu, E. \& Spiegelman, B. M. (1994). Stimulation of adipogenesis in fibroblasts by PPAR $\gamma 2$, a lipidactivated transcription factor. Cell 79, 1147-1156.

Tribble, D. L., Holl, L. G., Wood, P. D. \& Krauss, R. M. (1992). Variations in oxidative susceptibility among six low density lipoprotein subfractions of differing density and particle size. Atherosclerosis 93, $189-199$.

Turner, J. D., Le, N.-A. \& Brown, W. V. (1981). Effect of changing dietary fat saturation on low-density lipoprotein metabolism in man. American Journal of Physiology 241, E57-E63.

Utermann, G. (1987). Apolipoprotein E polymorphism in health and disease. American Heart Journal, 113, 433-440.

Valsta, L. M., Jauhiainen, M., Aro, A., Katan, M. B. \& Mutanen, M. (1992). Effects of a monounsaturated rapeseed oil and a polyunsaturated sunflower oil diet on lipoprotein levels in humans. Arteriosclerosis and Thrombosis 12, 50.57.

Wahrburg, U., Martin, H., Sandkamp, M., Schulte, H. \& Assmann, G. (1992). Comparative effects of a recommended lipid-lowering diet vs a diet rich in monounsaturated fatty acids on serum lipid profiles in healthy young adults. American Journal of Clinical Nutrition 56, 678-683.

Wardlaw, G. M. \& Snook, J. T. (1990). Effects of diets high in butter, corn oil, or high-oleic acid sunflower oil on serum lipids and apolipoproteins in men. American Journal of Clinical Nutrition 51, 815-821.

Wardlaw, G. M., Snook, J. T., Lin, M. C., Puangco, M. A. \& Kwon, J. S. (1991). Serum lipid and apolipoprotein concentrations in healthy men on diets enriched in either canola oil or safflower oil. American Journal of Clinical Nutrition 54, 104-110.

Watson, T. D. G., Caslake, M. J., Freeman, D. J., Griffin, B. A., Hinnie, J., Packard, C. J. \& Shepherd, J. (1994). Determinants of LDL subfraction distribution and concentrations in young normolipidemic subjects. Arteriosclerosis \& Thrombosis 14, 902-910.

Weinberg, R. B., Dantzker, C. \& Patton, C. S. (1990). Sensitivity of serum apolipoprotein A-IV levels to changes in dietary fat content. Gastroenterology $98,17-24$.

Weintraub, M. S., Zechner, R., Brown, A., Eisenberg, S. \& Breslow, J. L. (1988). Dietary polyunsaturated fats of the w-6 and w-3 series reduce postprandial lipoprotein levels. Chronic and acute effects of fat saturation on postprandial lipoprotein metabolism. Journal of Clinical Investigation 82, 1884-1893. 
Witztum, J. L., Young, S. G., Elam, R. L., Carew, T. E. \& Fisher, M. (1985). Cholestyramine-induced changes in low density lipoprotein composition and metabolism. I. Studies in the guinea pig. Journal of Lipid Research. 26, 92-103.

Xu, C. F., Boerwinkle, E., Tikkanen, M. J., Huttunen, J. K., Humphries, S. E. \& Talmud, P. J. (1990). Genetic variation at the apolipoprotein gene loci contribute to response of plasma lipids to dietary change. Genetic Epidemiology 7, 261-275.

Young, S. G., Witztum, J. L., Carew, T. E., Krauss, R. M. \& Lindgren, F. T. (1989). Colestipol-induced changes in LDL composition and metabolism. II. Studies in humans. Journal of Lipid Research 30, 225-238.

Zambon, A., Austin, M. A., Brown, B. G., Hokanson, J. E. \& Brunzell, J. D. (1993). Effect of hepatic lipase on LDL in normal men and those with coronary artery disease. Arteriosclerosis and Thrombosis 13, 147-153.

Zampelas, A., Murphy, M., Morgan, L. M. \& Williams, C. M. (1994). Postprandial lipoprotein lipase, insulin and gastric inhibitory polypeptide responses to test meals of different fatty acid composition: comparison of saturated, n-6 and n-3 polyunsaturated fatty acids. European Journal of Clinical Nutrition 48, 849-858.

Zilversmit, D. B. (1979). Atherogenesis: a postprandial phenomenon. Circulation 60, 473-485.

Zock, P. L., de Vries, J. H. M. \& Katan, M. B. (1994). Impact of myristic acid versus palmitic acid on serum lipid and lipoprotein levels in healthy women and men. Arteriosclerosis and Thrombosis 14, 567-575. 